\title{
APROXIMACIÓN METODOLÓGICA AL ESTUdIO DE LA TÉCNICA EDILICIA ROMANA EN HISPANIA, EN PARTICULAR EL OPUS TESTACEUM *
}

\author{
LOURDES ROLDÁN GÓMEZ \\ Universidad Autónoma de Madrid
}

\begin{abstract}
Este trabajo tiene como objetivo el estudio de los ladrillos romanos en la Península Ibérica. Para ello se tiene en cuenta tanto sus medidas y disposición como el espesor del mortero y otros aspectos de interés. La falta de sellos y las diferencias entre las diversas ciudades romanas no permiten precisar sin embargo, sus aspectos tipológicos y cronológicos.
\end{abstract}

\begin{abstract}
This paper aims to study an aspect of Roman architecture: the structure of brick pavements in some Roman cities in the Iberian Peninsula. We take into consideration the measurements of the bricks, the thickness of the mortar, the disposition of the wall and the position of the bricks. The lack of stamps and the big differences between Roman cities don't allow us to make cronological considerations about use and types of bricks.
\end{abstract}

La arquitectura romana ha sido largamente estudiada por diversos autores, cuyas obras, que no vamos a enumerar ahora, han tratado ésta desde diversos enfoques. La valoración de la arquitectura, como reflejo de una evolución histórica, se hace cada vez más evidente y necesaria, ya que responde a unos determinados fenómenos sociales, económicos y políticos.

El estudio de las técnicas constructivas constituye una faceta básica para el conocimiento de la arquitectura. A través de ellos podemos valorar, de una manera más clara, las manifestaciones arquitectónicas como expresión de la economía, cultura y la Historia, en general de una sociedad.

\footnotetext{
* El presente trabajo, realizado como Memoria de Licenciatura, se inscribe en el programa de investigación que promueve y dirige el Prof. M. Bendala Galán, Catedrático de Arqueología de la U. A. M., sobre arquitectura y edilicia en la Hispania romana. Se concreta ahora en un proyecto de investigación auspiciado por la Caicyt, del que forma parte la autora como becaria de investigación.
}

La elección de las técnicas y materiales constructivos están en muchos casos, motivada por fenómenos directamente relacionados con los acontecimientos históricos de cada pueblo y por sus condicionamientos técnicos. Por ello, es necesario efectuar trabajos de estas características en zonas geográficas restringidas y no tratar de trasponer las conclusiones obtenidas para unas zonas a otras, culturalmente distintas, o geográficamente alejadas.

Este estudio que aquí presentamos tiene interés en sí mismo ya que este tipo de trabajos no han sido realizados, hasta ahora en la Península (1) aunque, existe en Roma, y en Italia, en general, una larga

(1) Uno de los pocos publicados es el de León sobre la técnica edilicia en Itálica (1977-78). Hay también algunos trabajos sobre sellos latericios como los de Etienne y Mayet (1971) de Belo; García y Bellido (1968 y 1970) sobre los sellos de la Legio VII Gémina; Esteve y Guerrero (1961) de Asta Regia; Veny (1965) en Mayorca; Argente (1980) en Tiermes; Serrano Ramos y Luque Moraño (1976) en Cartama y Etienne, Fabre y L'Eveque en Conimbriga. Recientemente, Bermúdez (1986, 364-371) ha publicado un estudio sobre producción latericia basado en las tejas 
tradición al respecto; baste con citar los estudios de Blake y Lugli (2), cuyo propósito era conseguir la datación de los edificios a través de sus materiales constructivos, mediante el establecimiento de unos cánones (3). Estos venían determinados por una serie de características por las cuales se podría deducir una pauta cronológica. En el caso del opus testaceum se estudiaban características de los ladrillos tales como: composición, forma, corte, procedencia, medidas, sellos, grosor y calidad de la argamasa, etc... (4).

Dadas las diferencias existentes entre los edificios de Roma y la Península, tanto en posibilidades de estudio, como en características constructivas (5), consideramos necesario elaborar una metodología de trabajo propia. De este modo iniciamos el desarrollo de un método que sirviera, concretamente,

de la necrópolis Paleocristiana de Tarragona en las Jornadas Internacionales de Arqueología de Granollers.

(2) Van Deman (1912) publicó varios artículos sobre el tema y continuó recopilando información que no pudo ser publicada a causa de su muerte. Posteriormente, Blake (1947) recogió sus apuntes como guía para una publicación, continuando sus estudios sobre el tema en 1959 y 1973 . Más tarde, Lugli (1957), publicó su obra «La técnica romana edilicia.... que abarca fundamentalmente Roma y el Lacio. Los diferentes capítulos de esta obra analizan las técnicas constructivas empleadas por los romanos.

(3) Helen (1975), estudió 1815 marcas de ladrillo con el objeto de comprender la organización de los talleres y el significado de las mismas. Algo después, Setala (1977) retomó el problema de la producción de ladrillos romanos siguiendo las conclusiones de Helen. También Steinby (1973-74; 1974-75 y 1979), realizó estudios sobre el tema. La documentación que proporcionan los sellos resulta un complemento importantísimo para el estudio del opus testaceum.

(4) Posteriormente, se han realizado otros trabajos sobre técnicas constructivas como el de Gros (1978). Su obra tiene características muy diferentes a los anteriores autores ya que no trata de dar una evolución cronológica de la arquitectura, a través de las técnicas edilicias, sino que busca el porqué de ciertas manifestaciones arquitectónicas de cada momento y cada lugar, dentro del marco geográfico y cronológico estudiado: Roma e Italia centromeridional durante los dos últimos siglos de la República.

(5) Dadas las características de este estudio creemos necesario un conocimiento previo de las ciudades y edificios para ello. La falta de excavaciones y de publicaciones adecuadas, reduce mucho las posibilidades de elección. Por otro lado, es cada vez más evidente que existen grandes diferencias entre Roma y las provincias en las distintas facetas de su historia y de sus manifestaciones artísticas. Del mismo modo sucede en la arquitectura y técnica constructivas. para el estudio del opus testaceum, con la idea de que pudiera ser válido, con las convenientes variaciones, para otras técnicas constructivas.

Nuestro trabajo se basó, en principio, en los estudios existentes ya citados. Con su aplicación y el examen de los resultados pretendíamos establecer unas líneas generales sobre el inicio y la evolución de la técnica del opus testaceum en la Península, así como de su utilización y producción.

Para ello, era necesario obtener unos datos objetivos que pudiéramos cotejar, con espíritu crítico, con los conocidos en Roma. Ver, así, las diferencias y similitudes entre unos y otros y obtener las conclusiones derivadas de ello.

El objetivo inmediato era, pues, hacer una recopilación de datos de los edificios más significativos, en los que se utiliza el opus testaceum. Así, mediante un análisis sistemático y detallado del tipo de obra y del material utilizado dar, en la medida de lo posible, una pauta morfológica y cronológica.

Ante la multiplicidad de aspectos a estudiar y el elevado número de datos que creíamos necesario recoger, se imponía la necesidad de elaborar una ficha-tipo que ha sido aplicada en el presente trabajo. En ella están incluidos todos los elementos que, a nuestro juicio, son imprescindibles con la posibilidad de ampliar la información, siempre que se considere necesario, en el apartado de observaciones (6).

Con toda esta información recopilada, objetivamente, se podrán elaborar estadísticas y comparar las distintas características para obtener de ello, en la medida de lo posible una evolución de la técnica y unas conclusiones históricas.

La recopilación, completa y rigurosa, de este tipo de documentación obliga a la toma de datos directamente en los yacimientos como única manera de captar la disposición de los ladrillos, las características del aparejo, etc... También es posible, de esta manera, hacer una valoración del entorno y obtener una visión de conjunto que de otro modo sería imposible captar.

(6) Actualmente, se ha comenzado ya a aplicar un tipo de ficha semejante en el estudio sobre la arquitectura romana de la Bética, que realizamos en el departamento de Prehistoria y Arqueologia de la U. A. M. bajo la dirección del Dr. Bendala Galán, catedrático de dicho departamento. 


\section{METODOLOGÍA}

En consonancia con los presupuestos enunciados la realización del trabajo se planteó en tres niveles o escalones consecutivos:

I. - Recogida de datos.

II.-Elaboración de los mismos.

III.-Síntesis y Valoración.

I.-Para proceder a la recogida de datos elaboramos una ficha-tipo (fig. 1) (7), cuya utilización garantizará la objetividad y sistematización de los mismos, con objeto de poder realizar comparaciones entre ellos y en relación con otros edificios.

Cada ficha se refiere a un parámetro concreto, pudiendo haber varias de cada uno de los edificios - públicos o privados-de las ciudades estudiadas. Los criterios de selección de los puntos de cada edificio han sido los siguientes (8):

-representatividad de los paramentos.

- estado de conservación.

- ausencia de restauraciones.

- mayor o menor utilización del ladrillo.

Se ha cuidado, de manera especial, la ordenación de los puntos tomados en cada yacimiento, siendo numerados convenientemente y reflejados en un plano.

En cuanto a la toma de datos, propiamente dicha, ha resultado de gran utilidad el empleo de la ficha para mantener un orden preciso de ejecución evitando, así, errores o repeticiones (9).

Los datos más significativos para nuestro estudio han sido las medidas de los ladrillos y de las juntas de argamasa, así como la composición de unos y otras (10). También se ha tenido en cuenta el color

(7) La documentación que ofrece esta ficha se ordena en 4 niveles: 1. Localización-ubicación; 2. Información gráfica y fotográfica; 3. Datos morfológicos y tipológicos; 4. Datos complementarios.

(8) Los puntos elegidos han sido generalmente porciones de paramento, a veces esquinas, jambas y elementos arquitectónicos como columnas, etc...

(9) Se han tomado siempre primero las medidas de los ladrillos enteros, generalmente en esquinas, a continuación el resto siguiendo siempre el mismo orden: izquierda a derecha y de arriba a abajo.

(10) Consideramos que el único método completo para el estudio de la composición de los ladrillos es el análisis físicoquímico y mineralógico de los mismos. Estos análisis quedan, a nuestro pesar, fuera de las posibilidades de este trabajo de investigación.

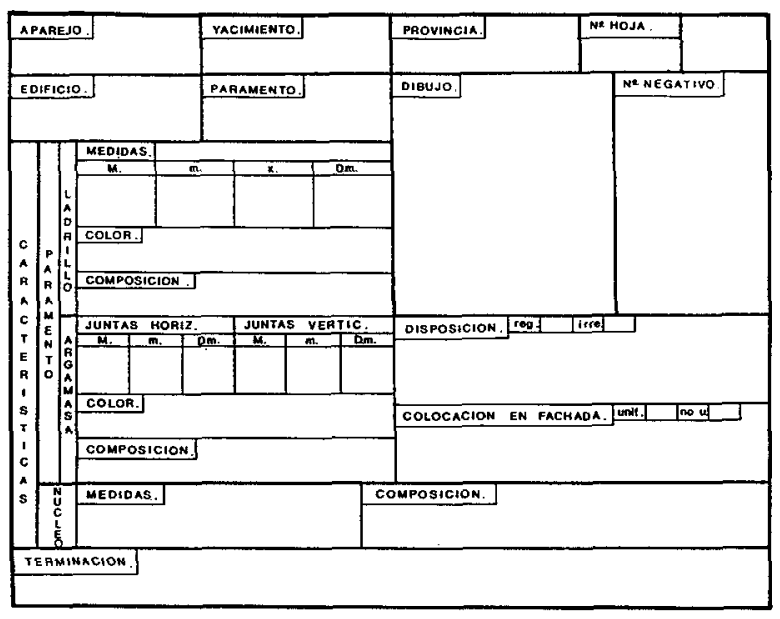

OQSERVACIONES

Fig. 1.-Modelo de ficha.

de los ladrillos aunque este dato, a pesar del empleo de un código de colores, puede resultar subjetivo o poco fiable (11).

La calidad en la construcción de un muro viene dada por la regularidad de éste y el esmero en la colocación de los ladrillos. Por ello, también se han considerado estos datos, así como las medidas de los muros; su composición; presencia de sellos, etc... Ha sido especialmente cuidada la representación gráfica y fotográfica de los paramentos estudiados (12).

(11) A veces el color varía mucho de unos ladrillos a otros en un mismo paramento; también pueden haber alterado éste las condiciones atmosféricas siendo el color interior diferente al exterior.

(12) Los puntos de cada edificio en que se han tomado datos están reflejados en su correspondiente plano. En cuanto a la documentación fotográfica ha constado de fotografías en blanco y negro y diapositivas a color. 


\section{ELABORACIÓN DE LOS DATOS}

Se trata, fundamentalmente, de la realización de estadísticas con los datos recogidos. Concretamente, se han realizado con las medidas de los ladrillos: largo, ancho y grueso, y con las juntas de argamasa horizontales y verticales. Hemos utilizado fundamentalmente la media, moda y desviación media, teniendo también en cuenta el porcentaje de la moda y la media de las desviaciones.

La media aritmética resulta una medida fictícia para los ladrillos ya que es una cifra intermedia, mientras que, en relación con las juntas de argamasa, sí resulta un valor apropiado. Sucede lo contrario con la moda que representa, en relación con los ladrillos, la medida más veces repetida.

La realización de estas estadísticas ha sido de gran utilidad para agrupar los datos en bloques homogéneos y comparar unos con otros.

Paralelamente al estudio de las medidas, se han considerado elementos a valorar las características de los paramentos, tales como disposición del muro y colocación de los ladrillos (13).

El estudio del entorno tiene también mucho sentido dentro de nuestro trabajo ya que no tratamos de estudiar la técnica edilicia de un paramento aislado, sino que lo encuadramos en su correspondiente habitación; ésta en el edificio al que pertenece y, cada edificio, dentro de su yacimiento. La utilidad de esta valoración es proporcionar una perspectiva amplia que permita comparar los datos obtenidos en cada edificio con el resto. Este estudio es fundamental para valorar justamente el significado del empleo del opus testaceum —en cada caso- dentro de su entorno geográfico, social, e histórico.

\section{SÍNTESIS Y VALORACIÓN}

Este último escalón corresponde, en realidad, a las conclusiones obtenidas de la propia metodología. Hemos analizado éstas en varios apartados:

(13) Entendemos por disposición del paramento, la regularidad o irregularidad en su ejecución, es decir, cuidado en la colocación de las hiladas de ladrillos; solidez del muro; buena técnica, etc... La segunda característica se refiere únicamente a la colocación de los ladrillos en cada hilada; es decir, si las caras largas están colocadas hacia la fachada y las cortas hacia el interior del muro o viceversa, y si esta colocación tiene o no una uniformidad. a) Medidas de los ladrillos: a través de las estadísticas se ha llegado a establecer cuáles son los valores límites entre los que se integran el resto de las medidas. Algunas de ellas se dan con mayor frecuencia y es lo que podríamos llamar «ladrillos tipo».

b) Uniformidad de las medidas: se establece mediante los porcentajes de la moda. El mayor o menor porcentaje reflejaría el grado de adaptación de los ladrillos de un paramento a una medida concreta. Se puede interpretar la moda como la tendencia general a una medida a la hora de fabricar los ladrillos. Ello no siempre se consigue, seguramente, por diferencias técnicas como cantidad de pasta empleada, cocción, secado, cortado, etc...

Estas diferencias podían alterar las medidas de los ladrillos aunque los moldes utilizados fueran idénticos.

Se puede considerar que para que las dimensiones de los ladrillos de un paramento sean uniformes la moda debe representar, al menos, el 50\%. De este modo, un elevado porcentaje de la moda supone una elaboración de los ladrillos más correcta.

También se puede analizar la regularidad de un paramento a través de la desviación media con respecto a la moda (14). Se ha considerado un paramento regular cuando la media de las desviaciones con respecto a la moda es inferior a 0,40 . La desviación media está relacionada con la selección de los ladrillos previa a la construcción. Si se cuida que los ladrillos que se van a emplear sean de medidas similares, entre sí, y que no haya ladrillos rotos o partidos, el valor de la desviación media sería bajo. Este valor numérico es mayor cuando existen algunos ladrillos, en el total, cuyas medidas difieren bastante de lo que sería la moda o la media.

c) Juntas: se puede establecer con sus medidas, al igual que con las de los ladrillos, una comparación entre los diferentes valores en un paramento de opus testaceum. La diferencia entre ambos refleja una mayor regularidad en los paramentos, lo cual implica un mayor cuidado en la ejecución que en caso contrario.

d) Módulo: el número de hiladas de ladrillo comprendidas en un metro de altura de paramento, o módulo, ha sido tomado como índice cronológico muy válido en el estudio del opus testaceum en

(14) Es decir, la media de las diferencias entre la moda y el resto de las medidas. 
Roma (15). Otro dato de interés, directamente relacionado con el módulo, es la relación entre ladrillo y argamasa - que hemos llamado ratio- en un paramento.

Además de estos datos que son los que reflejan, de una manera más clara, las diferencias y similitudes entre paramentos, edificios y ciudades, hay que considerar otra serie de características que complementan esta información. Nos referimos, concretamente, a la disposición general del muro; colocación de los ladrillos en fachada; dimensiones y solidez de los muros; técnicas y materiales a los que se asocian, etc... Todos estos elementos pueden indicar la calidad de un edificio y si representa la tónica general, o es una excepción en el entorno.

Considerando y valorando, de este modo, todos los datos citados se podrán establecer conclusiones parciales de cada edificio, yacimiento, etc... A partir de ellas y en conjunción con otros datos de tipo económico, social o histórico, se podrán llegar a definir pautas generales sobre el empleo del opus testaceum, en la Bética, como técnica edilicia.

Esta metodología ha sido aplicada en algunas ciudades de la Bética Romana, concretamente en Belo, Carteia, Itálica y Munigua (16). De su aplicación se han obtenido algunas conclusiones, tanto en sí mismas, como de la comparación de unas con otras y de todas ellas con Roma. Itálica ha proporcionado mayor cantidad de datos y, por tanto, más significativos (17).

\section{EVOLUCIÓN DE LA TÉCNICA Y MATERIALES CONSTRUCTIVOS EN LAS CIUDADES.}

Las características de estas ciudades, tanto sus condiciones históricas, como políticas, su status jurídico e incluso su desarrollo urbanístico es diferente

(15) Es comúnmente aceptado que el módulo como combinación del grosor de los ladrillos y las juntas horizontales, define etapas cronológicas del opus testaceum.

(16) Agradecemos a los directores de cada una de ellas la posibilidad de realizar este estudio.

(17) Está prevista la publicación de dos artículos en breve plazo sobre el opus testaceum en Itálica en edificios públicos y edificios privados. Por esta razón, y dado el gran número de puntos en los que hemos tomado datos, más de un centenar, no incluimos en este artículo las figuras correspondientes, y remitimos para estos detalles a los artículos siguientes: El opus testaceum en Itálica: edificios públicos y el opus testaceum en Itálica: edificios privados (en prensa). entre todas ellas. Sin embargo, exceptuando el caso de Carteia, la actividad constructiva va a estar ligada a la adquisición de su carácter jurídico. Por ello, en Itálica tiene lugar una remodelación al final de la época republicana (LEON, 1983, 220), Belo (MCV, 1980,419 y $1981,419,430$ ) y Munigua (GRUNHAGEN y HAUSCHILD, 1977, 108) adquieren importancia como ciudades al tiempo que reciben el rango de Municipios y es, a raíz de ello, cuando tiene lugar la construcción de sus edificios más importantes. Solamente Carteia no parece responder al mismo esquema y, a pesar de que se funda como Colonia en el 171 a. C., la época de mayor actividad constructiva hay que fecharla a fines del s. I a. C., o comienzos del s. I d. C. (18).

\section{CARTEIA (fig. 2)}

Los inicios de la vida de esta ciudad datan del s. IV a. C., con anterioridad a la presencia romana que tiene lugar en el s. II a. C. (19). En el último tercio de este siglo la ciudad comienza a acuñar moneda y adquiere importancia la industria de salazón (CHAVES TRISTAN, 1979, 33).

La construcción más antigua conocida es la muralla cuya técnica, indígena, consiste en el empleo de bloques de arenisca. En el período de mayor florecimiento de la ciudad - a fines de la República y comienzos del imperio - hay que datar algunos edificios como el foro y otros contiguos a él, así como algunas viviendas particulares. Las termas se construyen posteriormente $\mathrm{y}$, aunque sin cronología muy precisa, deben remontarse, al menos, a época Flavia (PRESEDO y CABALLOS, 1986). Su perduración debió ser larga a juzgar por los materiales hallados en la excavación.

Existen, además, otras construcciones de época tardía como el baptisterio de inmersión situado detrás del templo. Una serie de tumbas tardorromanas y visigodas son los testimonios más modernos de la ciudad.

(18) Conocemos la fecha de fundación por Tito Livio, 28, 30, 3. Presedo Velo y Caballos Rufino (1986), resumen las excavaciones y estado de la cuestión.

(19) En 1975 fue descubierto el yacimiento del Cerro del Prado (PELLICER Y OTROS, 1977), a $2 \mathrm{~km}$. al NO de la Carteia romana, hallando materiales desde el s. VIII ó VII a. C. al V ó IV a. C. En el s. IV ó III a. C. este emplazamiento perdió su función de puerto trasladándose a $2 \mathrm{~km}$. al SE de la costa, a la Carteia actual romana. 


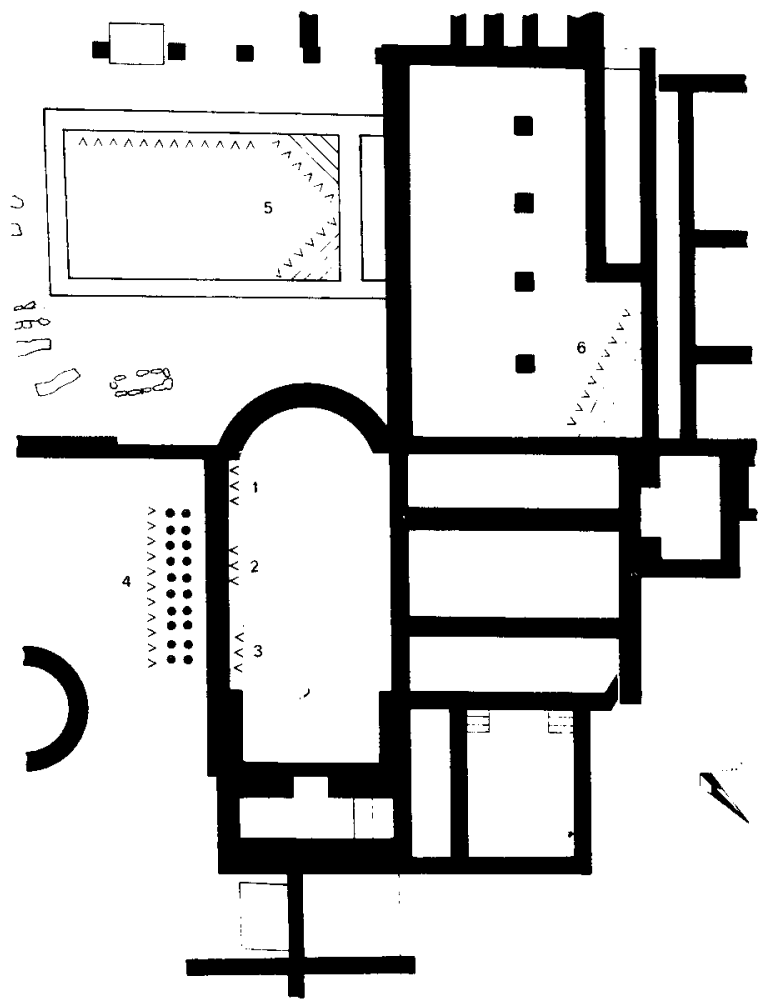

Fig. 2.-Carteia, plano de las termas (Presedo y Caballos Rufino, 1986). Toma de datos: caldarium, p. 1 a 3 ; hypocaustum, p. 4 y frigidarium, p. 5.

En cuanto a la técnica edilicia se utiliza, principalmente, la piedra en los edificios del s. I a. C.s. I d. C.. El ladrillo se emplea en las termas y también hay constancia de algunos ladrillos que proceden de casas particulares. Tanto en zonas públicas, como privadas, han aparecido tejas y ladrillos con las marcas CARTEIA, HERCULE y M. PETRUCIDIUS. M.P.LEG. PRO. PR.M.LICI (20).

El examen de la técnica constructiva empleada en las termas, único edificio donde es posible el estudio del opus testaceum, evidencia una serie de peculiaridades: los materiales utilizados son diversos: ladrillos, piedras pequeñas, sillares, opus caementicium, opus signinum, etc... Estos se distribuyen, estructuralmente, en función del carácter y utiliza-

(20) Estos fragmentos con marca se conocen ya desde antiguo. Romero de Torres $(1909,252)$ los cita y también Woods $(1967,253)$, quien supone que la presencia de tejas con marca Carteia demuestra el carácter público de las edificaciones. Presedo y otros $(1982,280-81)$ también los recogen junto con la polémica sobre el nombre Petrucidius, que parece corresponder a un legado de la Bética. ción de cada espacio. De este modo, únicamente, encontramos ladrillos en el caldarium, hypocaustum $\mathrm{y}$ frigidarium.

La pared común del caldarium y el hypocaustum es de ladrillos enteros y muy regulares. Miden, generalmente $28-29 \mathrm{~cm}$. de largo; $21-22 \mathrm{~cm}$. de ancho y 5, 5-6 cm. de grosor; aunque los hay de 28 a $30 ; 19$ a 22 y 5 a $7 \mathrm{~cm}$. Son regulares pues la moda representa del 75 al $80 \%$ del total y la desviación media de 0,13 a 0,28 . Las juntas de argamasa horizontales miden de 0,8 a $1,30 \mathrm{~cm}$. (lám. 1). Los ladrillos del frigidarium se colocan en las escaleras y en los muros, aunque éstos últimos son mucho más irregulares.

El empleo de ladrillos se reduce prácticamente a esto, añadiendo los de las columnas de hypocaustum - circulares- (Lám. 1a) y una conducción de agua. La distribución que se hace de ellos es racional ya que, los más uniformes, se colocan en el muro del caldarium y en las escaleras del frigidarium, quedando los más irregulares y rotos para los muros de este último, revestido de opus signinum. Aquí sigue existiendo un criterio selectivo: los ladrillos enteros se colocan en las caras internas del muro, lo que proporciona una mayor uniformidad para aplicar el revoco.

Como características constructivas en esta ciudad podemos apuntar, además del empleo de la piedra, ladrillo, opus caementicium y opus signinum, la relativa uniformidad de las construcciones en todo el yacimiento y las diferentes técnicas en relación con el tipo de edificio de que se trata. Así, por ejemplo, se emplea siempre la piedra en construcciones monumentales como el foro, el templo, etc..., y el ladrillo en edificios privados y en las termas, únicamente. La construcción de estas últimas es regular y cuidada, aunque los ladrillos son más o menos uniformes según las zonas.

La utilización de la piedra en las construcciones de Carteia se explica fácilmente ya que, existiendo un hábitat que puede remontarse al s. IV a. C., debió haber una gran tradición en el trabajo de la piedra. Este material se emplea en la construcción de la muralla y continúa en época romana junto con otras técnicas. La escasa utilización del ladrillo quizá no sea debido a una ausencia real sino, más bien, a falta de documentación. Siendo Carteia una ciudad suficientemente organizada para llevar a cabo esta producción y contando con terrenos arcillosos, propios para la fabricación de ladrillos, no se explica la escasez de este material en las construcciones. 


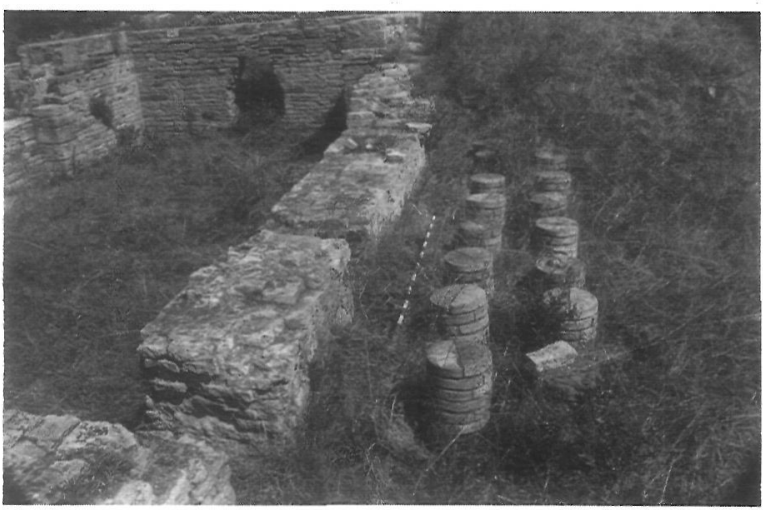

Lám. Ia.-Carteia, termas.

\section{BELO (fig.3)}

La ciudad de Belo nace en época romana siendo los materiales más antiguos del s. II a. C., o comienzos del s. I a. C. Durante este siglo se va desarrollando la industria de salazón y el comercio y, es en época de Claudio, cuando recibe el rango municipal y se convierte en una importante ciudad (DOMERGUE, 1973, 101 ss).

Los primeros vestigios constructivos datan de época de Augusto, pero la construcción de la ciudad romana que hoy conocemos tienen lugar en el s. I, con motivo de la adquisición de su status jurídico.

Se utilizan para ello materiales locales, principalmente, caliza conchífera y losa de tarifa. Está ausente el empleo del ladrillo.

Tras una época de cierta decadencia, en la que no hay evidencias constructivas, la ciudad resurge a fines del s. III o comienzos del s. IV con una población relativamente numerosa, a juzgar por los materiales. En este momento se levantan las termas y algún otro edificio de peor calidad.

La construcción de las termas se llevó a cabo mediante el empleo de piedras — con las que se realiza la mayor parte de la construcción-y ladrillos. Estos empleados en el hypocaustum, suspensurae y dobles paredes (lám. 2a), e importados del norte de África (21).

Los materiales utilizados responden a una tipología adecuada a su forma de empleo. Hay ladrillos de varias medidas:

(21) Véase en Mayet (1974, 95-105) la excavación de las termas y Etienne y Mayet $(1971,59-71)$ para el estudio de los ladrillos.

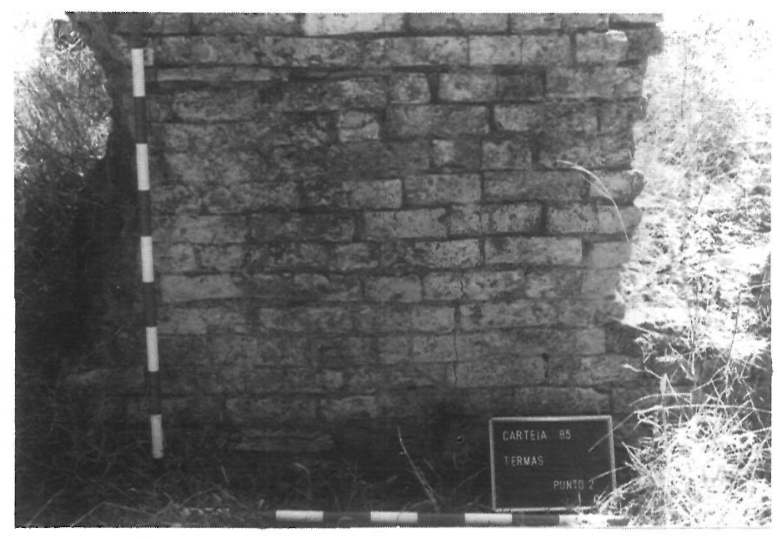

Lám. Ib.-Carteia, termas: muro de Caldarium.

a) Pequeños y muy regulares. La moda representa más del $40 \%$ del total y las desviaciones son inferiores a 0,40 ; miden entre $20-22 \mathrm{~cm}$. de largo; 14 a $16 \mathrm{~cm}$. de ancho y $3,5-4,5 \mathrm{~cm}$. de grosor. Muchos de ellos llevan sello con la marca IMP. AUG.

b) Ladrillos grandes, menos regulares. La moda representa el 30 al $60 \%$ y las desviaciones medias de 0,40 a 0,70. Miden 28-30 cm. de largo; $20-22 \mathrm{~cm}$. de ancho y 4,5-6 cm. de grosor. Las juntas horizontales miden $1,63 \mathrm{~cm}$. de media y 0,38 de desviación media.

c) Ladrillos bipedales para las suspensurae. Algunos llevan marcas.

d) Ladrillos de orejetas y con mamelones, algunos con marca.

$\mathrm{El}$ material latericio se introduce en Belo con un conocimiento de la técnica. La construcción de las termas evidencia un adecuado empleo de los materiales. la presencia de estos ladrillos en Belo señala las relaciones con el Norte de África, lo que también se constata en la utilización de una técnica típicamente africana, el llamado opus africanum (lám. 2b).

Como características constructivas de la ciudad se podría citar, en primer lugar, la utilización de materiales locales y de técnicas romanas como el opus caementicium, signinum, etc..., para un tipo de construcción genuinamente romana. En segundo lugar, la uniformidad de los materiales, ya que las diferencias técnicas responden a la cronología. Sólo se utiliza el ladrillo en las termas del s. IV.

El empleo de la piedra, como material constructivo fundamental en la Belo del s. I, se explica por la existencia de canteras cercanas que proporcionan 


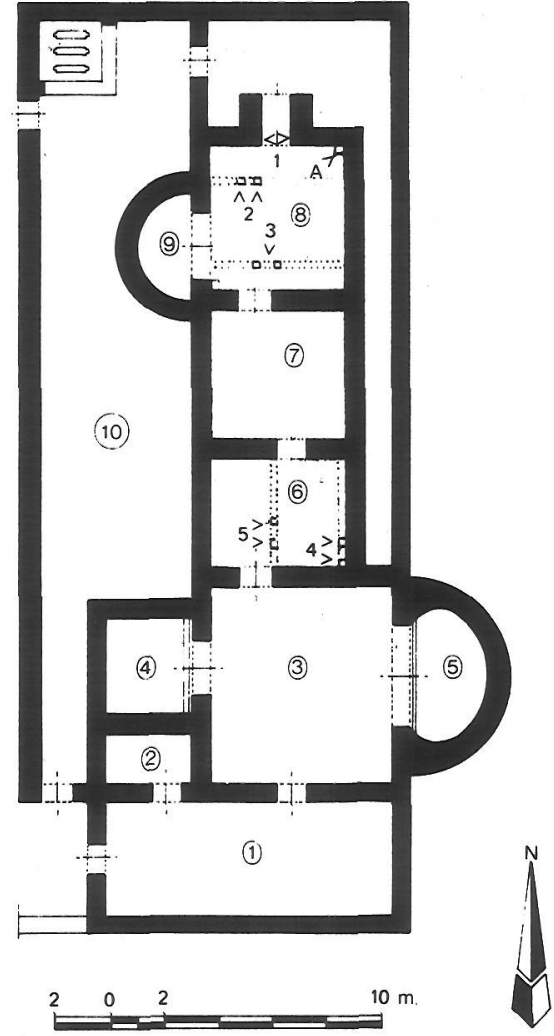

Fig. 3.-Belo, plano de las termas (Mayet, 1974). Toma de datos en el hypocaustum.

suficiente materia prima. Existen varios tipos de piedras a los que se dan diferentes usos, según la mayor o menor facilidad de la talla (DARDAIN y otros, 1983, 128 ss).

El aparente desinterés de esta ciudad por la fabricación de ladrillos queda patente cuando, en el s. IV, es preciso su uso y se importa del Norte de

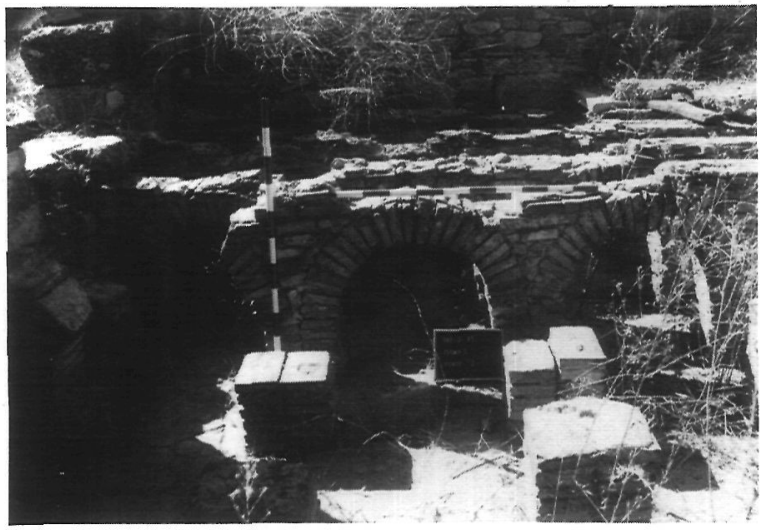

Lám. IIa.-Belo, termas: arquillos del hipocaustum.

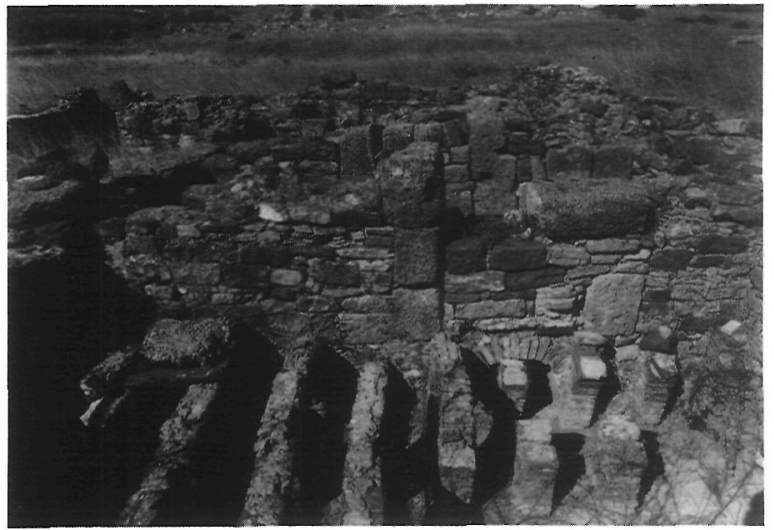

Lám. IIb.-Belo, termas: opus africanum.

África, en vez de fabricarlos. Quizá, en esta ciudad, no existiera una población suficientemente abundante como para rentabilizar la producción. Ello, referido a la experiencia en el trabajo de la piedra, daría como resultado una preferencia clara en el empleo de este material.

MUNIGUA (fig. 4 a 10)

El lugar donde se asienta la ciudad de Munigua estuvo habitado desde el s. IV a. C., aunque no se conoce establecimiento romano hasta finales del s. I d. C. El poblado iberoturdetano construyó sus casas con piedras y adobes (GRUNHAGEN, 1959 , 277). Sólo a partir del s. I d. C. existe un urbanismo romano unido a la introducción de materiales de construcción típicamente romanos: ladrillos; opus caementicium; opus signinum; estucos pintados, etc... Es entonces cuando recibe de Vespasiano el derecho de latinidad y se convierte en Municipium Flavium Munigensis. Como consecuencia se hace necesaria la construcción de nuevos edificios, entre ellos el Foro, templos, termas, etc..., imprescindibles para la integración de la ciudad en la vida municipal. Esta nueva situación alcanza su esplendor en el s. II (GRUNHAGEN y HAUSCHILD, 1977, 108) (fig. 4).

El establecimiento romano de Munigua debió estar en función del aprovechamiento del metal, como ya se venía haciendo desde el primer momento de habitación (22). A pesar de esta función la ciudad adquiere una gran monumentalidad, con un

(22) Se han hallado restos de canales de fundición en varios lugares de la ciudad. Grunhagen y Hauschild (1977, 108 y 1979, 291). 

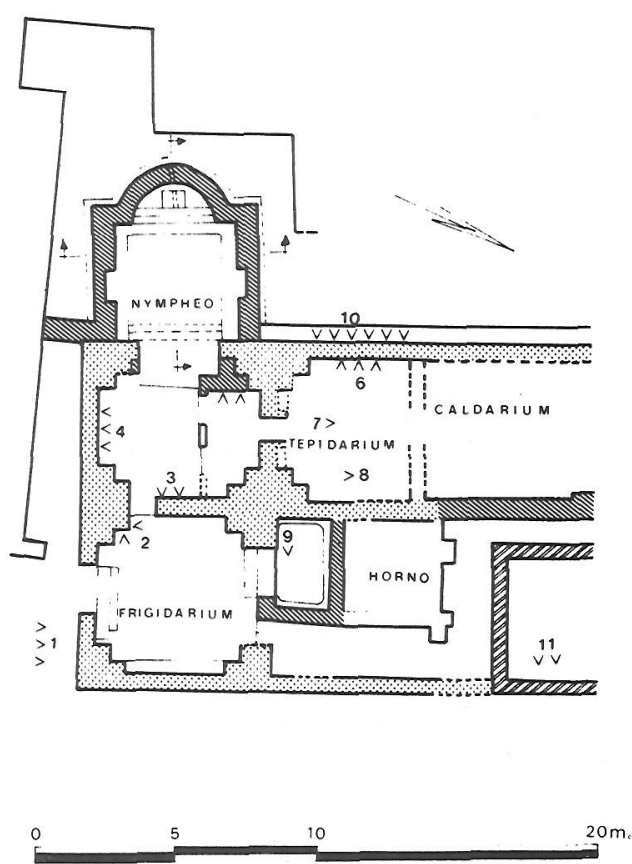

Fig. 4.-Munigua, plano de las termas (Grunhagen, 1977). Toma de datos: tepidarium, p. 6, 7, 8 y 10; sala contigua, p. 3, 4 y 5 ; frigidarium, p. 2.

urbanismo aterrado y un carácter religioso. Este se manifiesta por la existencia de un gran Santuario y dos templos (en una ciudad de reducidas dimensiones que no debió tener una población muy abundante) (23).

En relación con la técnica edilicia existe en Munigua una gran uniformidad. Todos los edificios levantados en el s. I poseen una construcción similar de muros de piedra y jambas y esquinas de ladri1lo. Este sistema es el empleado en el foro, las termas y algunas casas (lám. 3).

Los ladrillos utilizados en las termas (fig. 4) (24) miden 27 a $30 \mathrm{~cm}$. de largo; 20 a $22 \mathrm{~cm}$. de ancho y 6-7 cm. de grosor (lám. 3b). Los empleados en el foro (fig. 5) (25) con algo diferentes, ya que miden

(23) Quizá fuera ésta una ciudad al estilo de Belo, que aglutinaría, en determinados momentos, una población dispersa establecida en pequeños poblados cerca de las mismas, ya que no se ha hallado, por ahora, el caserío de la ciudad.

(24) Grunhagen y Hauschild $(1977,105-107)$ sobre la excavación de las termas. Los datos sobre medidas de ladrillos, etc..., están tomados in situ por nosotros.

(25) El foro y los edificios anexos a él han sido excavados en varias campañas; cfr: Grunhagen y Hauschild (1979, 281 y ss); Hauschild (1969b, 400-407); Idem (1969-70, 61-71) principalmente.

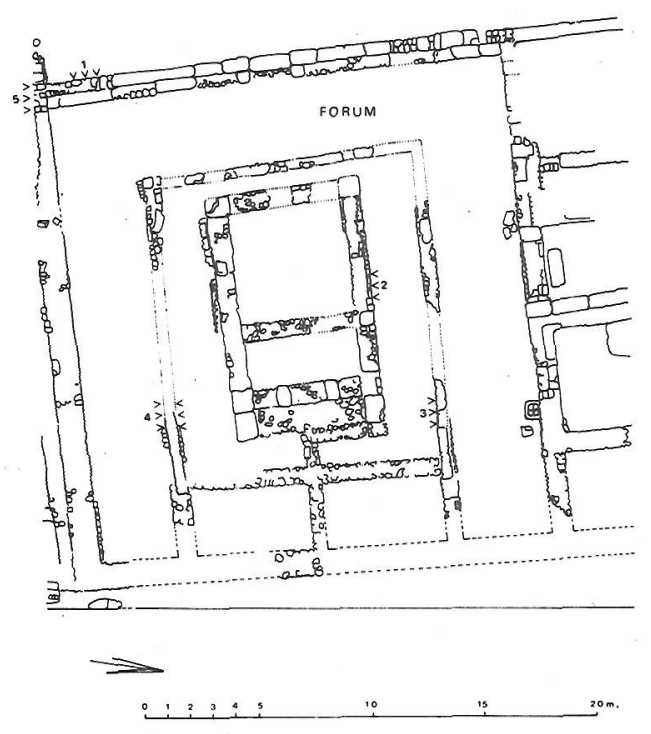

Fig. 5.-Munigua, plano del foro (Grunhagen, 1976). Toma de datos.

27 a $30 \mathrm{~cm}$. de largo; 21 a $24 \mathrm{~cm}$. de ancho y 5-6 $\mathrm{cm}$. de grosor. La uniformidad de las medidas es semejante en ambos: la moda representa el 40-60\% del total y las desviaciones son de 0,40 a 0,70 . Las juntas de argamasa coinciden en ambos edificios, siendo de 0,50 a $1,40 \mathrm{~cm}$. de grosor y desviaciones aproximadas de 0,30 .

La construcción de las casas (fig. 6 a 9) es algo más irregular ya que los ladrillos que se emplean miden 27 a $31 \mathrm{~cm}$. de largo; 17 a $24 \mathrm{~cm}$. de ancho y 5-7 cm. de grosor; en algún caso hay ladrillos rotos. El porcentaje de la moda varía entre el $30 \mathrm{y}$ el 70\%, siendo más uniformes los grosores. Las desviaciones son de 0,20 a 0,40 para los grosores y 0,50 a 1 para el resto de las medidas. (lám. 3a).

En el s. II se construye el Santuario de terrazas en el que existe mayor utilización de ladrillos (fig. 10). En gran parte se combina con la piedra pero es el único edificio con muros de opus testaceum concretamente se conserva la cella- (lám. 4a y b) (26). Otros edificios, como es el Templo del

(26) Fue comenzado a excavar por Grunhagen $(1959,275-$ 282). Para Grunhagen y Hauschild (1977, 105-107; 1979,299 y $1983,319-410)$ se trata de un gran edificio de planta axial y simétrica de tipo helenístico, construido mediante muros de contención, que se fecha a comienzos del s. II. Se supone dedicado a la Fortuna Primigenia o a Hércules y en relación con el culto al Emperador. 


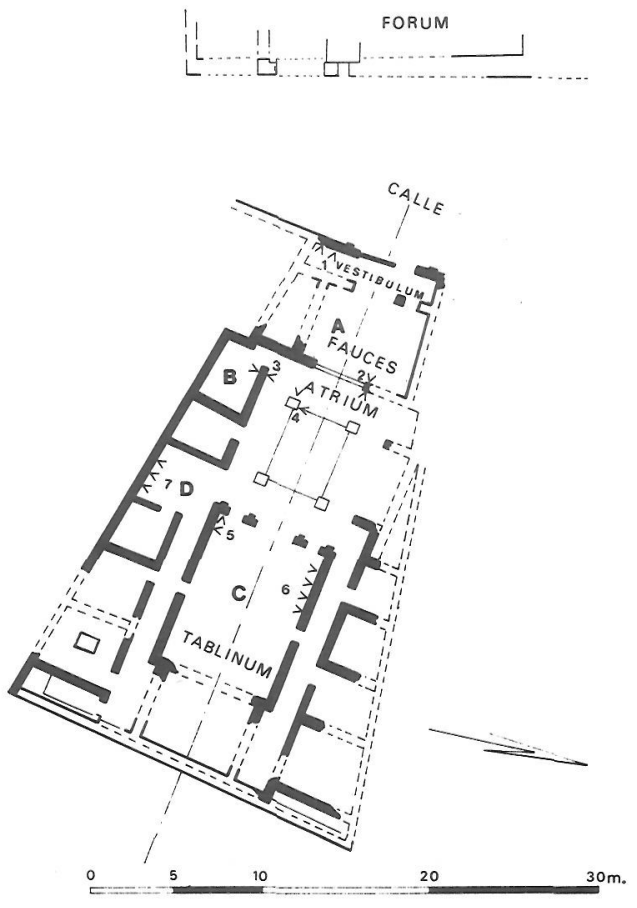

Fig. 6.-Munigua, casa n. ${ }^{\circ} 1$ (Hauschild, 1985). Toma de datos.

Podium coetáneo al Santuario; conserva los cimientos de los muros construidos en piedra.

Los ladrillos empleados en el Santuario son semejantes a los que se utilizan en edificios públi-

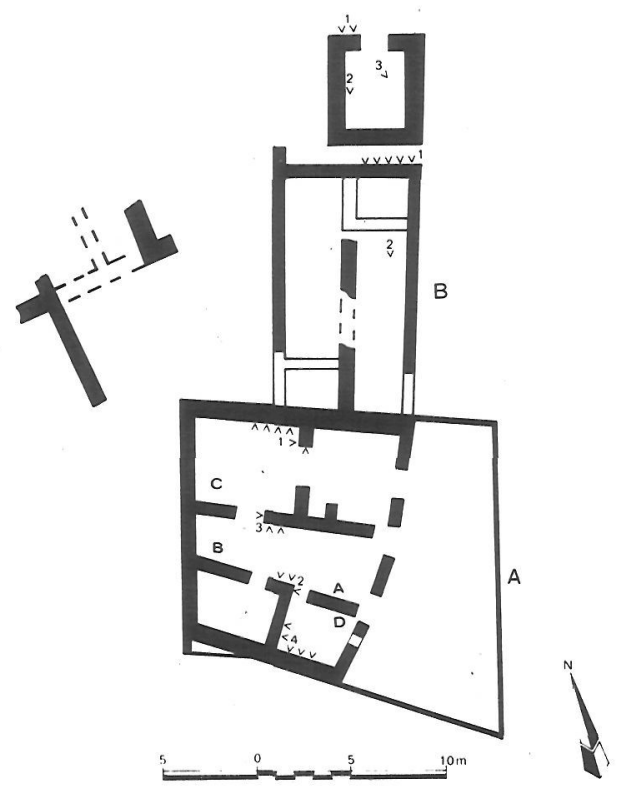

Fig. 8. - Munigua, casa n. ${ }^{\circ} 4$ y rampa de acceso al santuario (plano según Hauschild, 1985). Toma de datos.

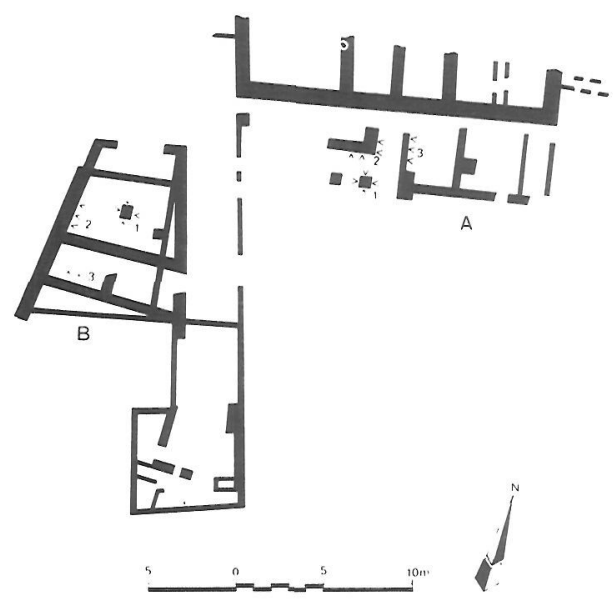

Fig. 7.-Munigua, planos de las casas $n .{ }^{\circ} 2$ y n. ${ }^{\circ} 3$ (Hauschild, 1985). Toma de datos.

cos del s. I. Miden 28,5 a $30,5 \mathrm{~cm}$; 21 a 24 y 5 a $7 \mathrm{~cm}$. respectivamente. Con porcentajes de la moda de 30 al $60 \%$ para anchos y largos y 45 a $75 \%$ en los grosores. Las desviaciones medias, con respecto a la moda, son de 0,28 a 0,50 en anchos y largos y 0,13 a 0,33 en los grosores. Las juntas horizontales miden $2 \mathrm{~cm}$. de media, algo más anchas que en los edificios públicos del s. I.

Existen algunos ladrillos de diferentes medidas que deben corresponder a un momento más tardio y se encuentran en la casa $n .^{\circ} 1$ y n. ${ }^{\circ} 3$. Los primeros, de ellos, cierran la puerta de una habitación, miden $30 \times 22-22,5 \times 6-6,5 \mathrm{~cm}$; los segundos estaban almacenados en el momento del derrumbamiento de la casa en el s. III, miden $28 \times 11 \times 5-6 \mathrm{~cm}$.
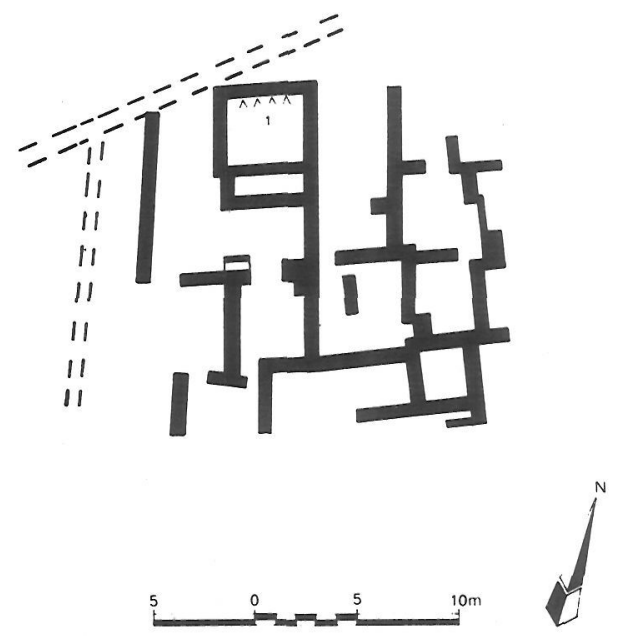

Fig. 9.-Munigua, plano de la casa n. ${ }^{\circ} 5$ (Hauschild, 1985). Toma de datos. 


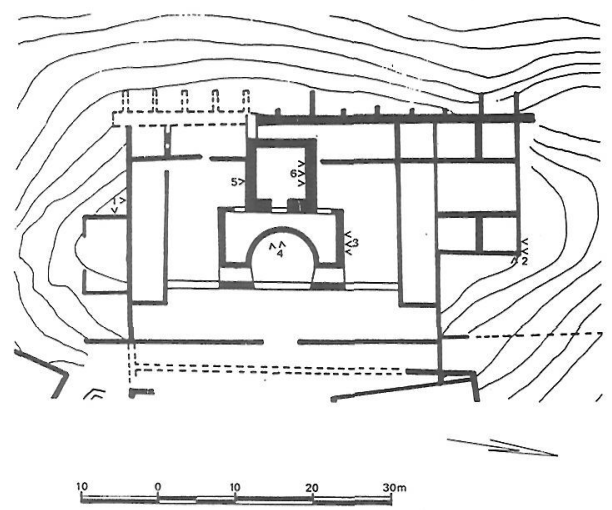

Fig. 10.-Munigua, santuario de terrazas (según Hauschild, 1985). Toma de datos.

En resumen, podemos resaltar las siguientes características en la actividad constructiva de Munigua: la utilización de piedras, ladrillos y, en algún caso, adobes o tapial; la similitud de la técnica regular y cuidada - tanto en edificios públicos, como privados, aunque con una mayor uniformidad en cuanto a medidas de ladrillos en los primeros. Todos presentan un acabado lujoso con mármoles y estucos pintados, que sin duda llevarían.

Se trata, pues, de un yacimiento en que se utilizan materiales romanos en combinación con los indígenas usados de antiguo.

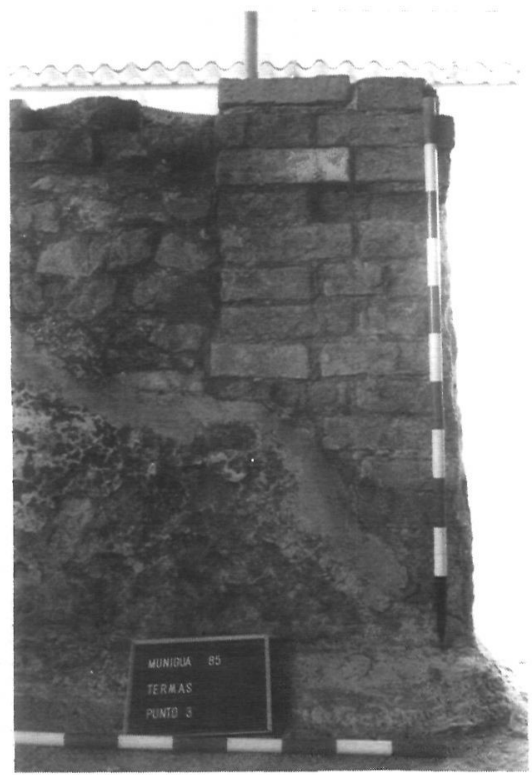

Lám. IIIb.-Munigua, pared de la terma.

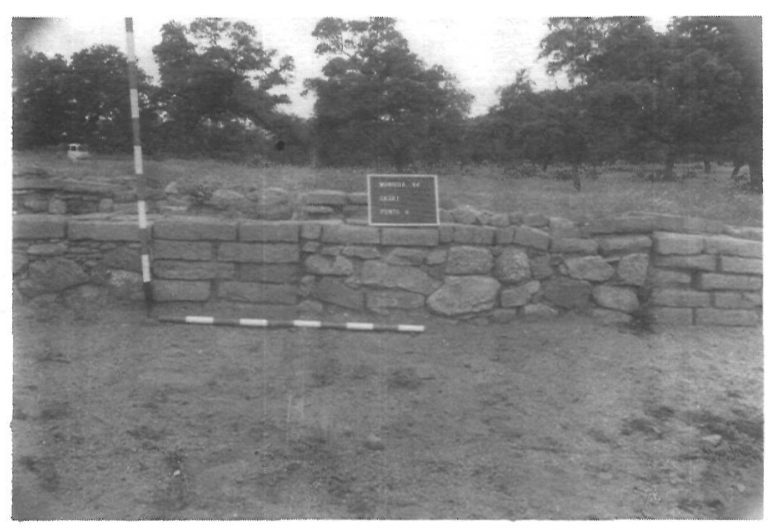

Lám. IIIa.-Munigua: muro de la casa $n .^{\circ} 1$.

El empleo del ladrillo es selectivo, a pesar de hallarse en una zona arcillosa donde no habría problema para obtener la materia prima. Quizá no llegará a existir en Munigua una infraestructura suficiente para justificar la presencia de fábricas de ladrillo, especialmente si se tiene en cuenta que la población no debió ser muy numerosa.

\section{ITÁLICA}

La ciudad tiene su origen en un campamento que se establece en este lugar en el 206 a. C., según fecha trasmitida por Apiano. Era una zona estratégica, bien comunicada y agrícolamente fértil. Al margen de que este asentamiento se realizara sobre una población indígena ya existente, o que el asentamiento de ambos fuera coetáneo (27), su vida se desarrolla en un ambiente típicamente turdetano hasta el s. I a. C., en que comienzan a aparecer materiales romanos. En este siglo conocemos ya algún edificio importante, como el teatro, y parece que tienen lugar algunas remodelaciones en la ciudad en relación con la adquisición de la categoría de municipio (LEÓN, 1983, 220).

Durante el s. I la ciudad continúa su desarrollo, como lo prueba la construcción del acueducto; o la muralla, con una fase anterior campamental y remo-

(27) Existen diferentes hipótesis sobre el primer asentamiento de Itálica; la estratigrafía de Pellicer $(1982,18)$ parece demostrar la existencia de una población desde el s. IV a. C... Corzo $(1982,310)$ se inclina a pensar en un asentamiento coetáneo de los núcleos indígena y romano, mientras que Luzón (1973) y Bendala (1975 y 1982) opinaba que se trató de una fundación «ex novo», basándose en sus excavaciones del Pajar de Artillo y Cerro de los Palacios. 


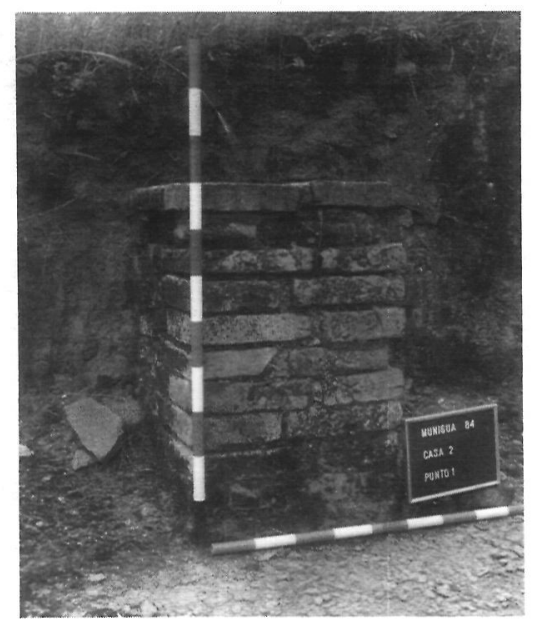

Lám. IIIc.-Munigua, pilar de la casa $n .^{\circ} 2$.

delaciones en el teatro (28). Además, existen algunos datos de otros edificios, como el foro, cuya construcción obligó a remodelar el sector y los edificios antiguos que se encontraban en él (CORZO, 1982, 311). En época de Trajano se construyen las termas.

Posteriormente, en el s. II, tiene lugar la planificación de la nova urbs con un gran derroche de medios, tanto en la planificación de los edificios públicos y privados, como en el suministro de materiales constructivos que parece corresponder al estado.

Como resumen de las características constructivas que se dan en Itálica se puede resaltar el empleo de materiales indígenas en un primer momento: cimientos de piedra, muros de tapial o adobe, techumbres de madera tanto en edificios privados como públicos y anteriores al s. I a. C., el templo republicano, Pajar de Artillo, C/ Trajano, 12.

Con la introducción de cerámicas romanas barniz negro y ánforas romanas- en el s. I a. C., comienza el uso de tejas y en el s. I d. C. se utiliza, normalmente, materiales romanos: hormigón, piedras, estucos, argamasa, etc... No se conoce el empleo del opus testaceum de forma sistemática, al menos en edificios públicos - teatro, acueducto, muralla - hasta que, en época de Trajano, se construyen las termas (lám. 5a).

(28) Consultar para la muralla: Jiménez (1977, 229-238); el acueducto: Canto $(1979,282-338)$ y teatro Luzón $(1982,183-20)$ y Jiménez (1982, 277-290).

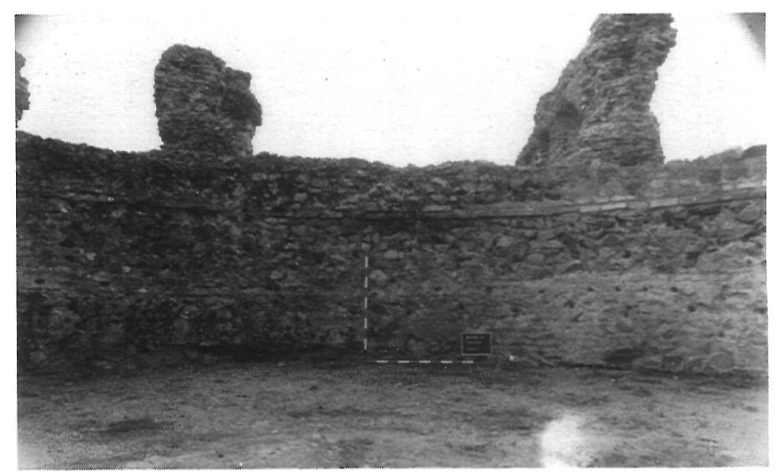

Lám. IVa.-Munigua, muro del santuario.

Hay evidencias de ladrillos en las excavaciones antes citadas que, presumiblemente, deben corresponder a época Flavia.

En los s. I y II d. C., los materiales romanos, incluido el ladrillo, han sustituido, por completo, a los tradicionales materiales constructivos de las poblaciones turdetanas. Singularmente, el adobe, tapial y las techumbres de paja o madera han dejado paso a los ladrillos y tejas; se mantiene únicamente, el uso de la piedra.

En cuanto a las técnicas y materiales constructivos empleados en la nova urbs existen diferencias entre edificios públicos y privados. Así, por ejemplo, la mayor cantidad de ladrillos se emplean en edificios públicos, además de materiales más cuidados o lujosos, como sillares almohadillados, mármoles, etc... Algunas características constructivas, como es el uso de encofrado y el empleo de ladrillos bipedales y sesquipedales, son propios sólo de edificios públicos (lám. 5b).

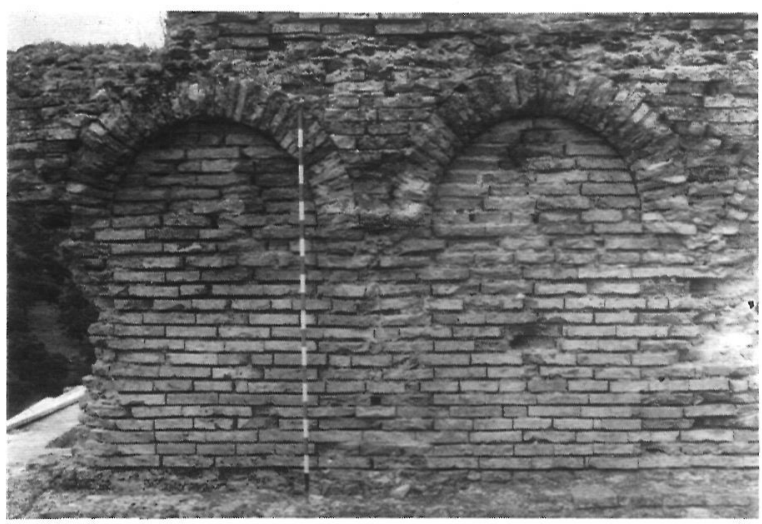

Lám. IVb.-Munigua, cella del santuario. 


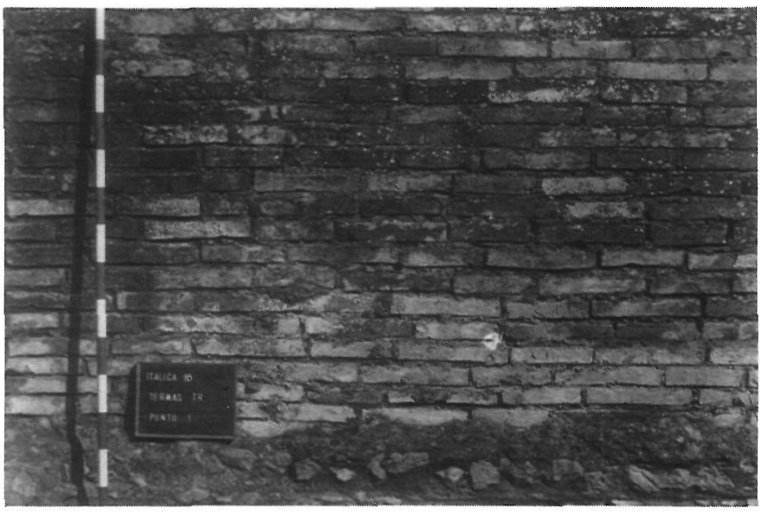

Lám. Va.-Itálica, termas de Trajano.

Las medidas de los ladrillos son más uniformes en los edificios públicos que en los privados. En éstos últimos se utilizan los mismos ladrillos - rotos o partidos - en gran cantidad, aunque las medidas, basándonos en los grosores, parecen indicar que se trata de los mismos tipos (29). Se aprecia, tanto en unos como en otros, cierta selección de los materiales, especialmnte apreciable en las casas particulares.

Resulta lógico, en una ciudad como Italica, el empleo de materiales constructivos tan romanos como el ladrillo.

Las posibilidades de obtener materia prima para su fabricación en las zonas arcillosas de la provincia, y la existencia de una abundante población, con una organización jerárquica, facilita la posibilidad de que existan fábricas y ladrillos. Abastecerían, principalmente, a edificios públicos y, únicamente, una pequeña parte de la producción iría destinada a los particulares. Estos se verían forzacios a utilizar, primordialmente otros materiales como piedras, guijarros, o, en ocasiones, opus caementicium. (lam. 6b).

\section{EL USO DEL LADRILLO EN EDIFICIOS PÚBLICOS}

El empleo de ladrillos en construcciones públicas varía de unas ciudades a otras y en función de

(29) Las medidas concretas de los ladrillos y otras características del opus testaceum de Itálica serán próximamente publicadas.

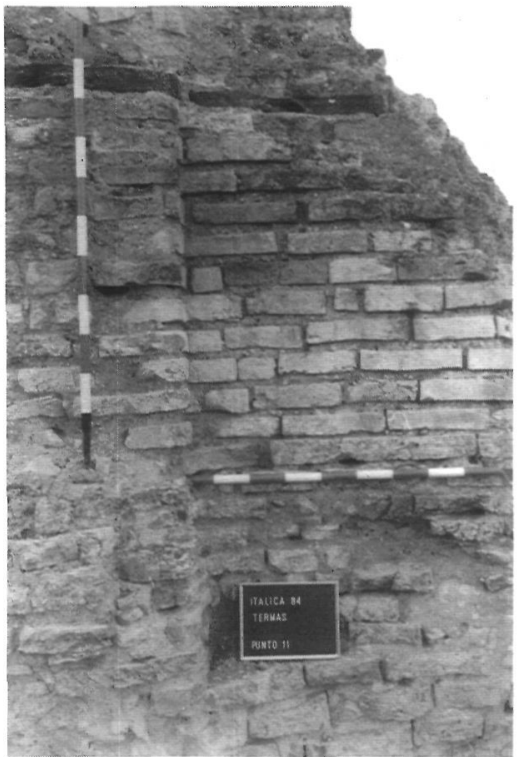

Lám. Vb.-Itálica, termas de la nova urbs.

los tipos de edificios. Así, por ejemplo, su uso se documenta en las cloacas y conducciones de agua con bastante asiduidad, tal es el caso de Munigua y Carteia y, sobre todo, de Itálica. En esta ciudad las construcciones hidráulicas en que se emplea este material datan del s. II, como sucede en la ampliación del acueducto para abastecer a la Nova

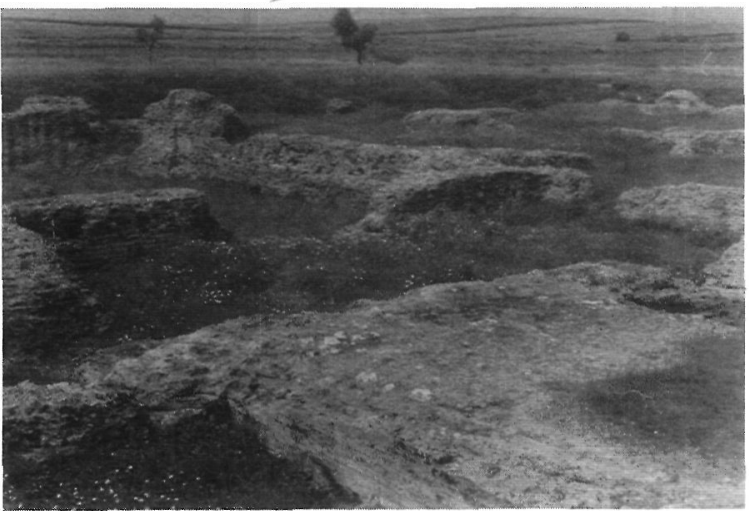

Lám. VIa.-Itálica, termas de la nova urbs. 


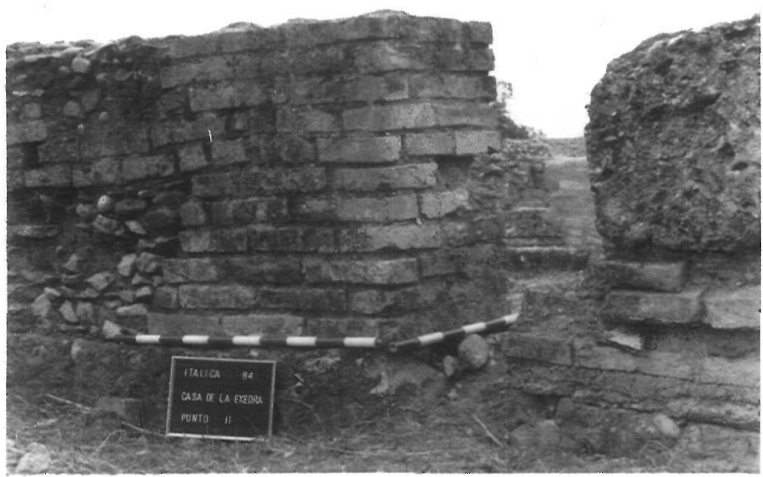

Lám. VIb.-Itálica, casa de la Exedra.

Urbs (30) y en las cloacas, especialmente las del anfiteatro. Este es uno de los edificios más importantes realizados en opus testaceum en Itálica, por su perfección técnica. Actualmente, se conserva en buen estado gracias a haber estado rellena de tierra durante muchos años y al escaso uso que debió tener en época romana.

También encontramos gran cantidad de ladrillos en los edificios termales. En Itálica se utilizan, tanto en las de Trajano, como en las de nova urbs, siendo éstos su principal material constructivo. Su uso también está atestiguado en las de Munigua (lám. 7b), Carteia y Belo - del s. IV- aunque no con la importancia que adquiere en Itálica (31). Por otro lado, estos edificios se prestan al empleo de una variada tipología latericia como podemos ver en Belo (32).

Por el contrario, en los templos se utiliza, generalmente, la piedra. En Belo los templos del s. I están construídos en piedra. También en Munigua, en construcciones de comienzos del s. II, como son

(30) Fue estudiado por Canto (1979, 22-338). Éste es el único edificio en Itálica en que hay ladrillos triangulares, cfr. Canto (1979, 314).

(31) En Munigua se combina con hormigón y piedras unidas con argamasa, dejando el ladrillo, principalmente, para jambas, esquinas e hiladas horizontales en medio de paramentos de piedra. Grunhagen y Hauschild (1977, 105-117). En Carteia y Belo su uso es prácticamente exclusivo del hypocaustrum.

(32) En las termas hay ladrillos de las medidas siguientes: -arquillos del hipocaustrum: $30 \times 20 \times 5 \mathrm{~cm}$.

-arquillos del hipocaustrum: $15 \times 20 \times 5 \mathrm{~cm}$.

-ladrillos bipedales: $60 \times 45 \times 7 \mathrm{~cm}$.

-ladrillos con mamelones y orejetas.

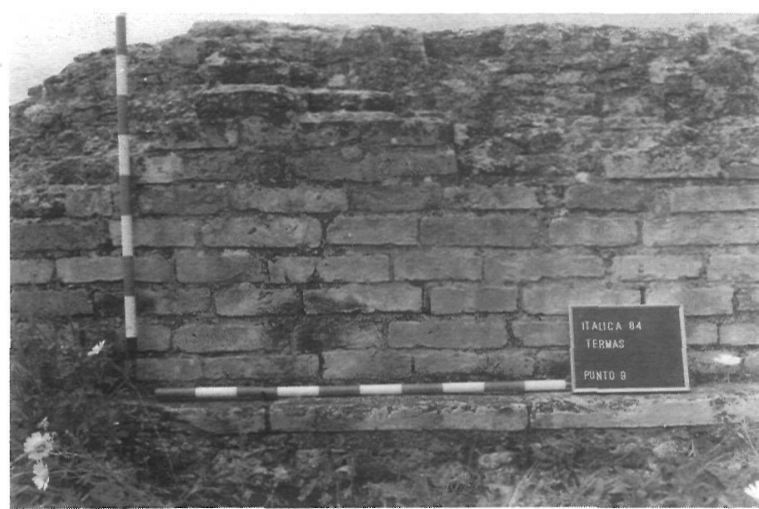

Lám. VIIa.-Itálica, termas de la nova urbs.

el Santuario de Terrazas y el templo del Podium, aunque en el primero se combina con el ladrillo. Apenas contamos con algún vestigio de templos en Itálica pero, en ellos, no se utiliza el ladrillo como material constructivo (34).

Los teatros constituyen edificios en los que el empleo del ladrillo está ausente. Como ejemplo de ello se podría citar los de Belo y Carteia, del s. I., realizados en piedra (35). El teatro de Itálica, del s. I a. C., y con remodelaciones posteriores, se construyó en piedra tufácea para, en el s. II., introducir un podium de ladrillo (lám. 8a y b). No conocemos la existencia de ladrillos en teatros de otras ciudades de la Bética como pueden ser Malaca, Acinipo, Regina Turdulorum, etc... En muchos de ellos se utilizaron grandes bloques de piedra tallada recubriendo núcleos de opus caementicium y se completaron con materiales más lujosos, como el mármol.

Paradógicamente, en el anfiteatro de Itálica se utilizó el opus testaceum de forma muy abundante (lám. 9a). Este edificio, del s. II., es uno de los más impresionantes de la Bética por su tamaño, características constructivas y conservación. Supone todo un derroche de técnicas y materiales ya que, para su construcción, se precisaron grandes cantidades

(33) Según Grunhagen y Hauschild $(1977,108)$ lo único conservado del templo del Podium son los muros de piedra a nivel de cimientos.

(34) El supuesto capitolio según Bendala $(1975,861-869)$ está realizado en piedra y adobe y del Trajaneum se conserva una plataforma de hormigón, León (1982, 97-132).

(35) En Carteia únicamente se conservan las gradas y poco más. Cfr. Woods y otros $(1967,7)$. De su alzado aunque destruído, Cfr. Ponsich (1980, 309-326) y Gilbert Picard (1970, 43-52). 


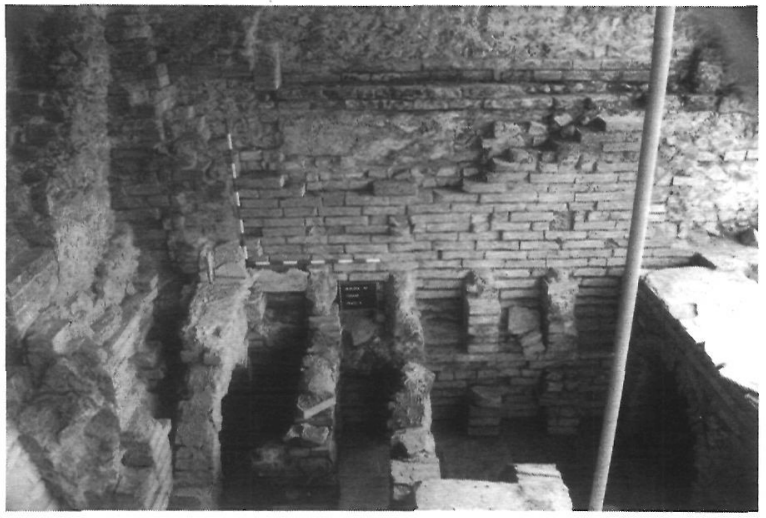

Lám. VIIb.-Munigua, termas.

de sillares, opus caementicium, ladrillos, mármoles, etc...

En contraste con la uniformidad de aparejos que se dan en los edificios públicos, las casas particulares suelen emplear materiales variados. Así, por ejemplo, en Belo se utiliza la piedra calcárea y el gres del país para la construcción de casas. Estas presentan algunos rasgos decorativos como capiteles, esculturas, pinturas, etc... En Carteia, entre los escasos restos de casas particulares, podemos constatar un tipo semejante al de Belo, ésto es, de peristilo, con materiales lujosos y elementos típicamente romanos: mosaicos, hypocaustum, pavimentos de ladrillo, etc... Seguramente utilizaron también ladrillos en los muros, aunque no han aparecido «in situ». En ellos hay que resaltar la presencia de algunos sellos de tegulae o ladrillos.

Las casas de Munigua no muestran, apenas, diferencias técnicas con respecto a los edificios públicos. Tanto unas, como otros, emplean una técnica

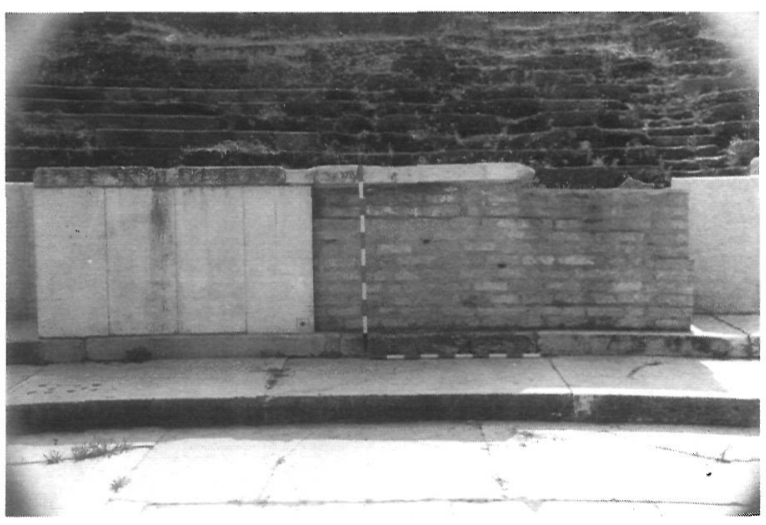

Lám. VIIIb.-Itálica, podium del teatro.

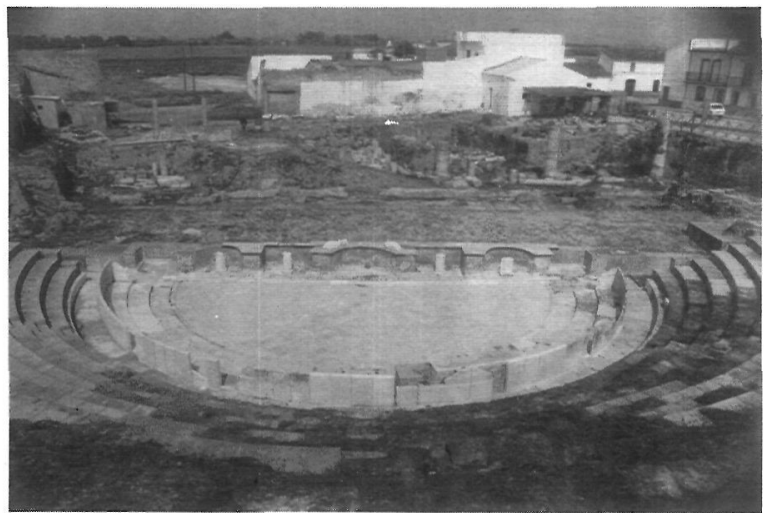

Lám. VIIIa.-Itálica, teatro.

que combina la piedra con el ladrillo y, en ocasiones el tapial. Esta técnica se utilizó en el s. I en las termas y el foro (HAUSCHILD, 1969-0, 66-67), así como en las casas particulares (HAUSCHILD, 1985, 235-268) (lám. 10a y b).

Hay que resaltar la variedad de materiales constructivos que se emplean en las casas de Italica. Aquí, existen grandes diferencias en las técnicas y materiales, según las categorías; incluso, dentro de ellas, los materiales son diferentes en las partes de servicio y las principales (36) (lám. 11a y b).

La variedad que se advierte en los elementos constructivos que se utilizan en los edificios privados debe responder, lógicamente, tanto al gusto de los propietarios, como a su capacidad adquisitiva.

\section{CARACTERÍSTICAS DEL MATERIAL LATERICIO}

A la vista de los datos obtenidos se puede considerar que, el empleo del ladrillo, se introduce en la Bética a mediados del s. I d. C. (37). En ningún caso aparecen anteriormente ya que, los ladrillos documentados en Itálica, en estratos de época Imperial, deben corresponder al período Flavio.

(36) La casa de la Exedra presenta una calidad constructiva superior al resto, dentro de ella se pueden diferenciar zonas más o menos importantes, según el empleo de materiales más o menos modestos. Este edificio se ha interpretado como de carácter público. Parladé $(1934,16)$ la describe como termas y Carriazo (1935), como gimnasio.

(37) En la casa de Venus de Itálica hay ladrillos de $30 \times 23 \times 5$ $\mathrm{cm}$. pertenecientes a una pileta, en un nivel fechable entre el s. I a. C. y s. I. d. C., según Pellicer y otros $(1982,15)$. 


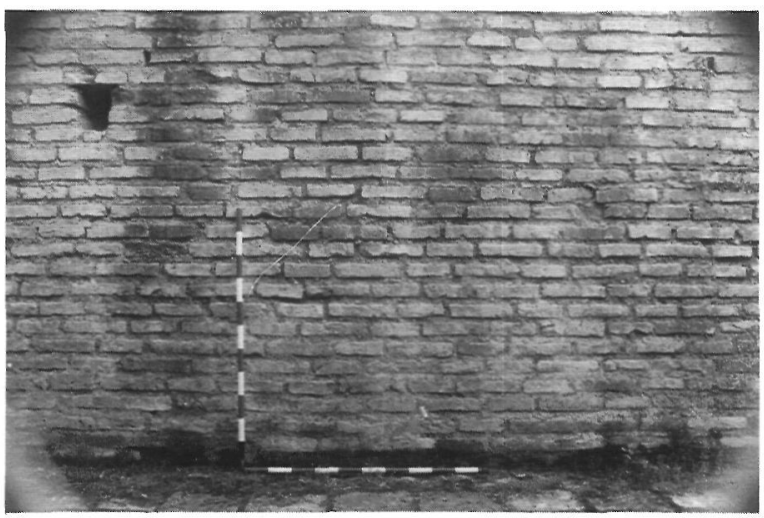

Lám. IXa.-Itálica, anfiteatro.

El empleo del opus testaceum debe generalizarse en la segunda mitad del s. I, tanto en construcciones públicas, como privadas. Al menos, así está atestiguado en Munigua y en Itálica, - termas de los Palacios- en época de Trajano (38). Los ladrillos documentados en Carteia son también del s. I. y de medidas muy similares a los de Munigua. Sin embargo, no se han incluido las de Belo en los cuadros comparativos por corresponder al s. IV.

a) Medidas de los ladrillos en el s. I

- Edificios públicos:

En los edificios que podemos datar en este período no vemos gran similitud en las medidas de los ladrillos, pero sí unos límites —máximos y mínimos- para todos ellos, relativamente cercanos (cuadro I). Los ladrillos que se utilizan en las termas de Trajano tienen un grosor inferior al resto: de 4 a $5 \mathrm{~cm}$. Ello proporciona un módulo de 16 hiladas, por metro, más acorde con la técnica del s. I. en Roma, que las medidas de Munigua y Carteia (39).

(38) La perfección de la técnica empleada en estas termas indica el grado de conocimiento en su aplicación conseguido durante el s. I d. C.

(39) Hemos comparado las termas de Trajano de Itálica con los edificios públicos de Carteia y Munigua por considerar las medidas de sus ladrillos más acordes con las de este siglo que con las del s. II. Estas medidas son similares a las de los ladrillos hallados en la excavación de la C/Trajano 12 en un nivel Imperial que podría considerarse de época Flavia, cfr. Bendala (1982, 37), estos ladrillos miden:

- $30,3 \times 22,4 \times 4,4 \mathrm{~cm}$.

- $30,1 \times 22,3 \times 4,7 \mathrm{~cm}$.

$-30 \times 21,9 \times 5 \mathrm{~cm}$.

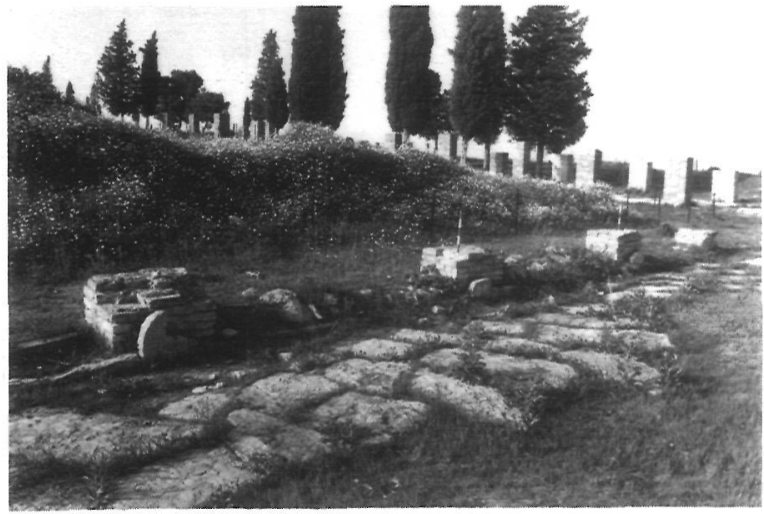

Lám. IXb.-Itálica, decumano.

- Edificios privados:

Únicamente, se han podido documentar los edificios de Munigua ya que en Itálica, las casas excavadas, corresponden al s. II y en Carteia sólo existen hallazgos aislados.

Las medidas de los ladrillos son muy similares a las de los edificios públicos, aunque con límites algo más amplios (ver cuadro 1).

Al comparar las medidas de los ladrillos utilizados en Munigua entre edificios públicos del s. I y privados se puede comprobar que existe una semejanza en ellas, aunque con una mayor regularidad en los primeros. Mientras que las juntas de argamasa son idénticas (cuadro 1).

También se ha podido comprobar que los ladrillos empleados en las termas de Trajano son más uniformes y los grosores algo más estrechos que los empleados en Munigua y Carteia para la construcción pública, en el s. I, -muy semejantes entre sí-.

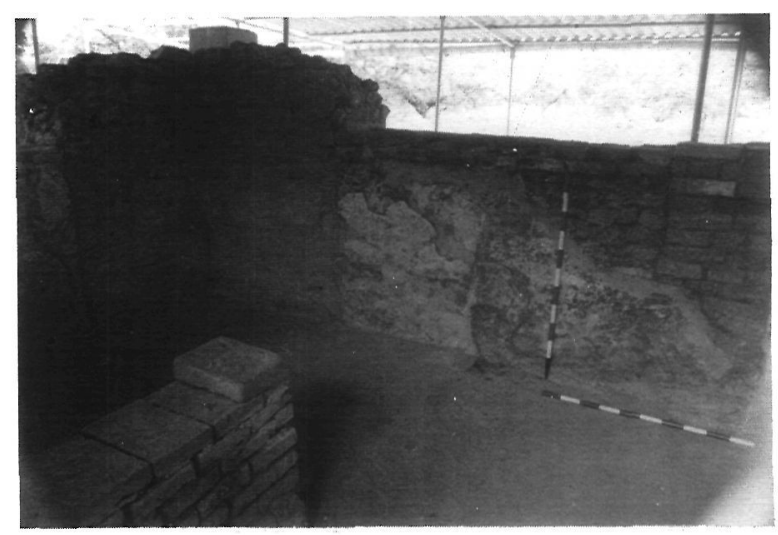

Lám. Xa.-Munigua, termas. 


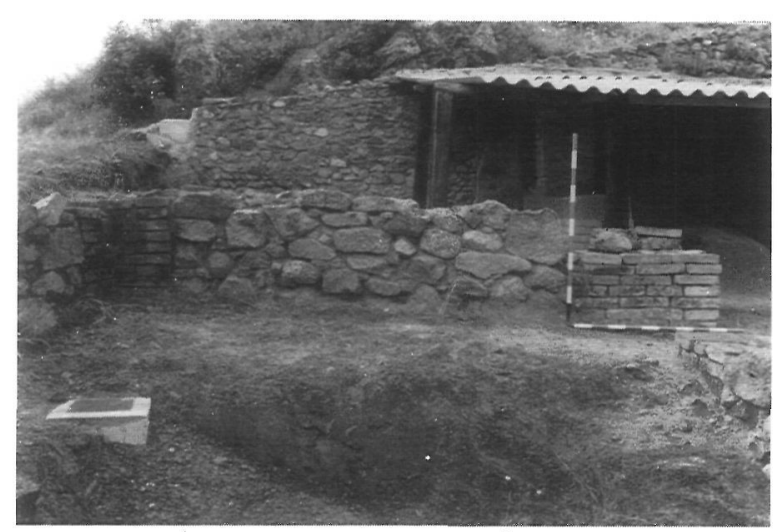

Lám. Xb.-Munigua, casa n. ${ }^{\circ} 4$.

Las juntas son algo más gruesas y uniformes en los edificios Italicenses (cuadro 1).

b) Medidas de los ladrillos en el s. II

Continúa la utilización de ladrillos, a gran escala, en los edificios fechados en este siglo. En Munigua se emplea en el Santuario de las terrazas - de comienzos del s. II-, aunque se combina con piedras (40). Sin embargo, donde existe un mayor uso del opus testaceum es en Itálica, tanto en edificios públicos, como privados. (Las medidas correspondientes al s. II, se recogen en el cuadro 2).

Del mismo modo que sucede en Munigua en el s. II, los ladrillos empleados ahora en Itálica, para edificios públicos, son más uniformes que los de los edificios privados. Las juntas también lo son, aunque con grosores muy similares (cuadro 2).

En general, los edificios públicos son más regulares que los privados, tanto en el s. I como en el s. II. Las juntas de argamasa serán siempre muy semejantes en ambos tipos de construcción en el siglo I; posteriormente, en el s. II, serán un poco más gruesas e irregulares en la construcción privada (cuadro 3);

Comparando el s. I con el s. II, apreciamos una progresiva evolución, en los edificios públicos, hacia una mayor regularidad en las medidas de los ladrillos, aunque muy leve, mientras, las juntas se irán haciendo más gruesas (cuadro 3). No ocurrirá lo mismo en los edificios privados, con una mayor irregularidad y grosor en las juntas del s. II.

(40) Consultar los detalles de este templo en Grunhagen y Hauschild (1977, 108; 1979, 200 y 1983, 324).

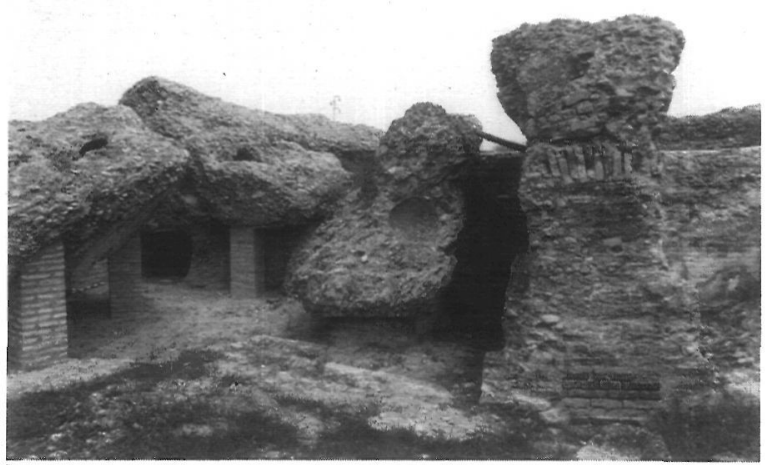

Lám. XIa.-Itálica, casa de la Exedra.

\begin{tabular}{|c|c|c|c|c|}
\hline & & $\begin{array}{l}\text { EDIFICIOS } \\
\text { PÚBLICOS } \\
\end{array}$ & $\begin{array}{l}\text { EDIFICIOS } \\
\text { PRIVADOS } \\
\end{array}$ & RESULTADO \\
\hline $\begin{array}{c}\text { MUNIGUA } \\
\text { s. I }\end{array}$ & \multirow{4}{*}{$\begin{array}{l}\mathrm{l} \\
\mathrm{a} \\
\mathrm{d} \\
\mathrm{r} \\
\mathrm{i} \\
\mathrm{l} \\
\mathrm{l} \\
\mathrm{o} \\
\mathrm{s}\end{array}$} & $\begin{array}{c}27-30 \\
19-24 \\
5-7\end{array}$ & $\begin{array}{c}27-31 \\
18-24 \\
5-7\end{array}$ & $\begin{array}{l}\text { Semejantes, más } \\
\text { irregulares los } \\
\text { de ed. privados }\end{array}$ \\
\hline $\begin{array}{c}\text { CARTEIA } \\
\text { s. I }\end{array}$ & & $\begin{array}{c}28-30 \\
19-23 \\
5-7 \\
\end{array}$ & -- & - \\
\hline \multirow[t]{2}{*}{$\begin{array}{c}\text { ITÁLICA } \\
\text { Trajano }\end{array}$} & & $\begin{array}{c}29-31 \\
21-24 \\
4-5 \\
\end{array}$ & -- & - \\
\hline & & $\begin{array}{l}\text { Más uniformes } \\
\text { y menos gruesos } \\
\text { los de Itálica }\end{array}$ & -- & -- \\
\hline
\end{tabular}

\begin{tabular}{|c|c|c|c|c|}
\hline $\begin{array}{c}\text { MUNIGUA } \\
\text { s. I }\end{array}$ & \multirow{4}{*}{$\begin{array}{l}\mathrm{j} \\
\mathrm{u} \\
\mathrm{n} \\
\mathrm{t} \\
\mathrm{a} \\
\mathrm{s}\end{array}$} & $0,5-1,5$ & $0,5-1,5$ & $\begin{array}{l}\text { Iguales los de } \\
\text { ed. públicos } \\
\text { que privados }\end{array}$ \\
\hline $\begin{array}{c}\text { CARTEIA } \\
\text { s. I } \\
\end{array}$ & & $0,8-1,3$ & -- & - \\
\hline \multirow[t]{2}{*}{$\begin{array}{c}\text { ITÁLICA } \\
\text { Trajano }\end{array}$} & & $1-1,8$ & -- & - \\
\hline & & $\begin{array}{c}\text { Algo más } \\
\text { gruesas } \\
\text { las de Itálica }\end{array}$ & -- & -- \\
\hline
\end{tabular}

Cuadro 1 


\begin{tabular}{|c|c|c|c|c|}
\hline & & $\begin{array}{l}\text { EDIFICIOS } \\
\text { PÚBLICOS }\end{array}$ & $\begin{array}{l}\text { EDIFICIOS } \\
\text { PRIVADOS }\end{array}$ & RESULTADO \\
\hline $\begin{array}{c}\text { MUNIGUA } \\
\text { s. II }\end{array}$ & \multirow{4}{*}{$\begin{array}{l}1 \\
\mathrm{a} \\
\mathrm{d} \\
\mathrm{r} \\
\mathrm{i} \\
\mathrm{l} \\
1 \\
\mathrm{~d} \\
\mathrm{~s}\end{array}$} & $\begin{array}{c}28-30,5 \\
21-24 \\
5-6\end{array}$ & -- & -- \\
\hline $\begin{array}{c}\text { CARTEIA } \\
\text { S. II }\end{array}$ & & - & -- & -- \\
\hline \multirow[t]{2}{*}{$\begin{array}{c}\text { ITALICA } \\
\text { s. II } \\
\end{array}$} & & $\begin{array}{c}26-31 \\
20-24 \\
4,5-6,5\end{array}$ & $\begin{array}{c}26-32 \\
17-24 \\
4-7\end{array}$ & $\begin{array}{c}\text { Más irregulares } \\
\text { los de edificios } \\
\text { privados }\end{array}$ \\
\hline & & $\begin{array}{l}\text { Algo más } \\
\text { regulares los } \\
\text { de Munigua }\end{array}$ & -- & -- \\
\hline
\end{tabular}

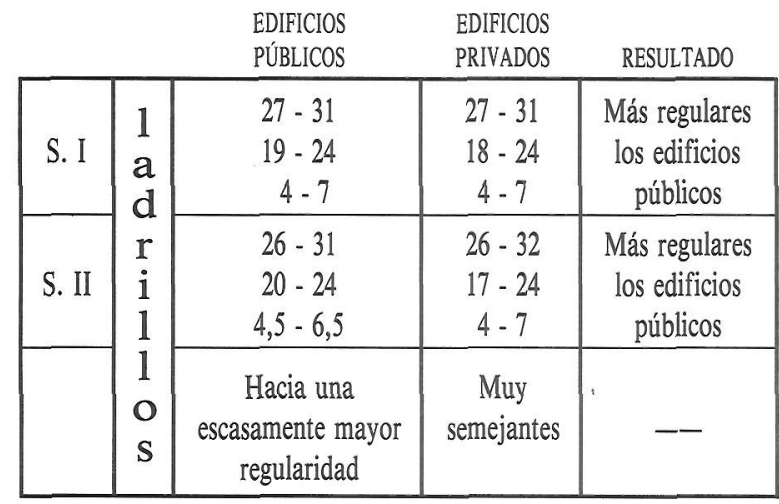

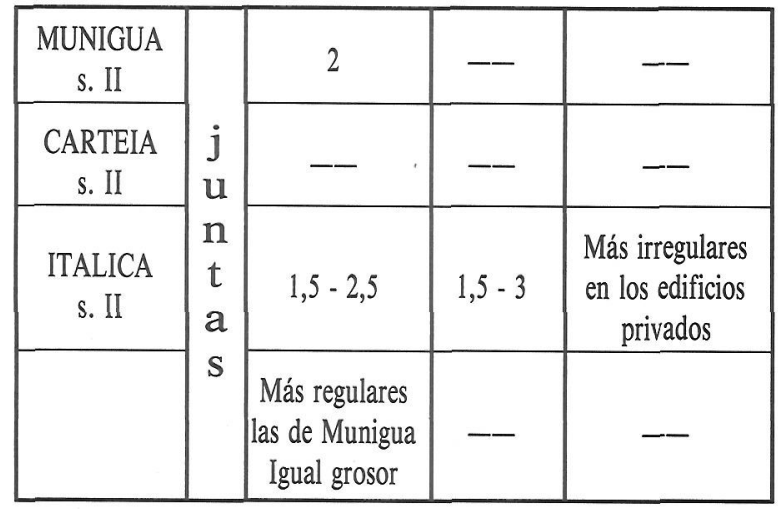

Cuadro 2

\section{c) Módulo y ratio}

En Itálica, el módulo en las termas de Trajano es de 15,5 a 17 hiladas por metro, con excepciones de 15 a 18 hiladas. El porcentaje de ladrillos, es algo superior que en las construcciones públicas del s. II -73 a $80 \%$, siendo el de argamasa de 27 a $20 \%$ -

Como se puede comprobar en el cuadro n. ${ }^{\circ} 4$, existe una disparidad en los módulos y en los porcentajes de ladrillo y argamasa de los distintos paramentos. Suelen ser más regulares los módulos empleados en edificios públicos que en privados, aunque en todos ellos hay excepciones. La ratio es bastante similar en ambos.

Convendría destacar, principalmente, dos datos interesantes. En primer lugar, el módulo que se emplea en Itálica - termas de Trajano- es mayor

\begin{tabular}{|c|c|c|c|c|}
\hline S. I & $\mathbf{j}$ & $0,5-1,8$ & $0,5-1,5$ & Muy semejantes \\
\cline { 1 - 3 } S. II & $\mathbf{u}$ & & & Más gruesas y \\
& $\mathbf{n}$ & $1,5-2,5$ & $1,5-3$ & $\begin{array}{c}\text { más irregulares } \\
\text { en el S. II }\end{array}$ \\
\cline { 4 - 5 } & $\mathbf{a}$ & Hacia un & Hacia un & \\
\cline { 3 - 5 } & $\mathrm{S}$ & mayor grosor & mayor grosor & - \\
\hline
\end{tabular}

Cuadro 3

al empleado en Munigua y Carteia, en el s. I (cuadro 4); ello es debido a un menor grosor de los ladrillos (ver cuadro 1). En segundo lugar, hay que señalar la evolución sufrida por el módulo del s. I al s. II. En este último, el módulo disminuye, es decir, el número de ladrillos empleados, por metro de altura de paramento, es menor que en el s. I (cua-

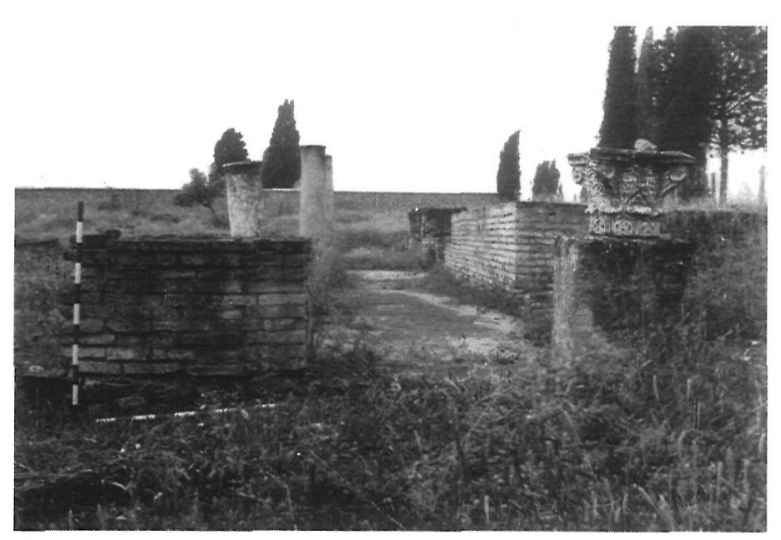

Lám. XIb.-Itálica, casa de Hylas. 


\begin{tabular}{|c|c|c|c|c|}
\multicolumn{1}{c}{} & \multicolumn{2}{c}{ EDIFICIOS PÚBLICOS } & \multicolumn{2}{c|}{ EDIFICIOS PRIVADOS } \\
\cline { 2 - 5 } \multicolumn{1}{c|}{} & MÓDULO & RATIO & MÓDULO & RATIO \\
\hline $\begin{array}{c}\text { MUNIGUA } \\
\text { S. I }\end{array}$ & $13-15 \mathrm{~h} / \mathrm{m}$ & $\begin{array}{c}1.80-86 \% \\
\text { a. } 20-14 \%\end{array}$ & $13,5-15,5$ & $\begin{array}{c}1.78-90 \% \\
\text { a. } 22-10 \%\end{array}$ \\
\hline $\begin{array}{c}\text { CARTEIA } \\
\text { S. I }\end{array}$ & $14-14,5 \mathrm{~h} / \mathrm{m}$ & $\begin{array}{c}1.81-89 \% \\
\text { a. } 19-11 \%\end{array}$ & -- & -- \\
\hline $\begin{array}{c}\text { ITALICA } \\
\text { Trajano }\end{array}$ & $15,5-17 \mathrm{~h} / \mathrm{m}$ & $\begin{array}{c}1.73-80 \% \\
\text { a. } 20-27 \%\end{array}$ & -- & -- \\
\hline
\end{tabular}

\begin{tabular}{|c|c|c|c|c|}
\multicolumn{1}{c}{} & \multicolumn{2}{c}{ EDIFICIOS PÚBLICOS } & \multicolumn{2}{c|}{ EDIFICIOS PRIVADOS } \\
\cline { 2 - 5 } \multicolumn{1}{c|}{} & MÓDULO & RATIO & MÓDULO & RATIO \\
\hline $\begin{array}{c}\text { MUNIGUA } \\
\text { s. II }\end{array}$ & $13 \mathrm{~h} / \mathrm{m}$ & $\begin{array}{c}1.70-75 \% \\
\text { a. } 30-25 \%\end{array}$ & -- & -- \\
\hline $\begin{array}{c}\text { CARTEIA } \\
\text { s. II }\end{array}$ & -- & - & -- & -- \\
\hline $\begin{array}{c}\text { ITALICA } \\
\text { S. II }\end{array}$ & $12,5-14 \mathrm{~h} / \mathrm{m}$ & $\begin{array}{c}1.67-81 \% \\
\text { a. } 33-19 \%\end{array}$ & $12-14$ & $\begin{array}{c}1.64-79 \% \\
\text { a. } 36-21 \%\end{array}$ \\
\hline
\end{tabular}

Cuadro 4

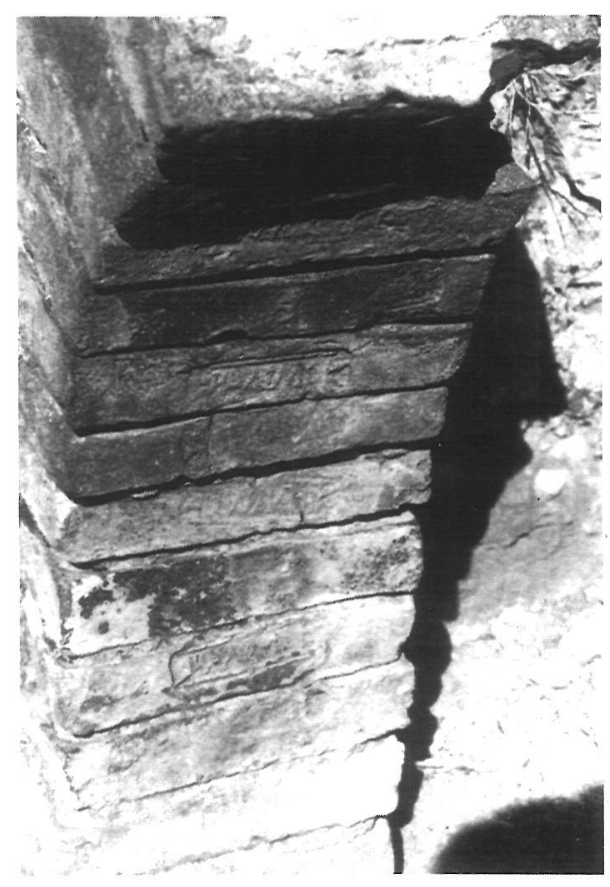

Lám. XIIb.-Belo, sellos de las termas.

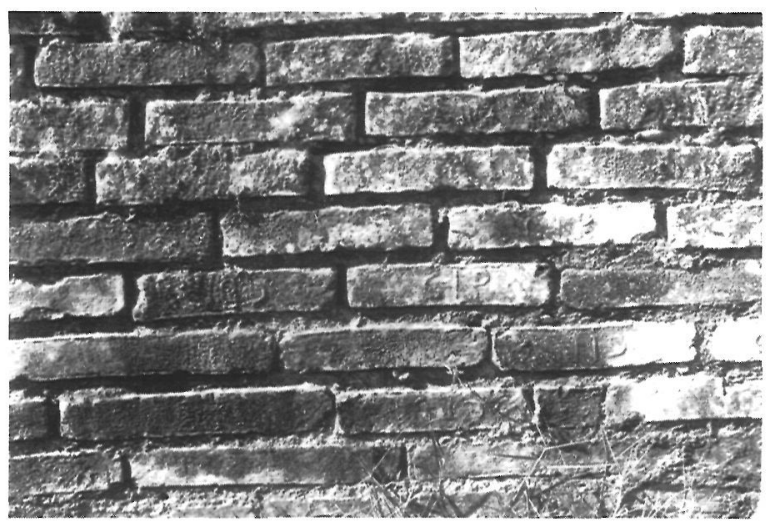

Lám. XIIa. - Itálica, sellos de las termas de Trajano.

dro 4). Ello se debe a un aumento del grosor de los ladrillos y, en mayor proporción, de las juntas de argamasa (cuadro 1 y 2 ).

De este modo, el porcentaje de ladrillos disminuye, con resecto al $\mathrm{s}$. I, en tanto que aumenta la proporción de ésta última (cuadro 4).

d) Industria y sellos

Los sellos son considerados como uno de los elementos fundamentales en la datación de los edificios en Roma. Ello es debido al conocimiento que se tiene de la industria latericia, lo que no ocurre en la Península. Por el momento no nos es posible datar los edificios de la Bética por este método, harían falta algunos estudios previos.

Sin embargo, la realización de este tipo de trabajo es difícil de llevar a cabo en la península, por no existir suficientes elementos para ello. Los sellos conocidos son poco abundantes, están documentados en Belo, Carteia, Itálica y algunos otros yacimientos (41), pero sus características tipológicas y cronológicas son diferentes entre todos ellos y distintos, a su vez de los hallados en Roma.

En Carteia los sellos encontrados llevan las marcas CARTEIA, HERCULE, M. PETRUCIDIUS. Este último alude al nombre de un procónsul de la Bética que podría ser propietario de alguna pequeña industria o controlar, de alguna manera, la producción de la ciudad (42).

(41) Ver supra nota 16.

(42) Sobre estos sellos ver Presedo y otros (1982, 280-281) y Albertos $(1966,181)$. 
Los ladrillos con marcas hallados en Itálica pertenecen, únicamente, a las termas de Trajano y su proporción en este edificio es alta (lám. 12a). Llevan el sello sobre la cara corta vertical, sin cartela, no sobre la horizontal como suele ser habitual en los ladrillos romanos. Se ha supuesto que las letras podrían aludir a unos trianomina (43) y según GARCÍA y BELLIDO $(1960,108)$, la I podría aludir a Itálica. En el primer caso se trataría de una fábrica perteneciente a un particular, en el segundo, podría tratarse de una fábrica municipal. En el s. I los fabricantes de ladrillos en Roma estaban en manos de particulares, lo que también está constado en la Península en Conimbriga (44). Además, no sería difícil encontrar nombres de personajes importantes de Itálica con estas iniciales (45). La fabricación de ladrillos en el s. II d. C., debió encuadrarse dentro de un plan constructivo. De este modo, las fábricas locales producirían expresamente, para abastecer a los edificios públicos de la nova urbs.

Además de éstos, se han hallado en Itálica ladrillos con el sello de la Legio VII Gémina, sin embargo, no conocemos el contexto en que han aparecido, ni los edificios a que podrían pertenecer. García y Bellido (1970, 22 y 23), ha fechado estos ladrillos en el s. II, por lo cual corresponden a una época avanzada de la construcción de Itálica en la que ya se estaban utilizando ladrillos de manera habitual.

Por último, las marcas de Belo, bien estudiadas por Etienne y Mayet proceden, como hemos dicho, del norte de África. Estas fábricas debieron producir una cantidad de ladrillos bastante considerable, serían imperiales a juzgar por el sello, lo cual no es extraño ya que en esta época también las fábricas de ladrillos romanas habían pasado a manos del emperador (lám. 12b).

(43) «Si se admite la época de Adriano como origen del funcionamiento de las fábricas imperiales de ladrillos (MAYET, 1974, 100 ), en el caso italicciense habría que pensar en fábricas particulares o, tal vez, locales». León (1977-78, 146).

(44) Las marcas de ladrillos halladas, identifican nombres como propietarios de fábricas: Primus, Avitus, Maellus, etc... Cfr. Etienne, Fabre y L'Eveque (1976, 134-136).

(45) León (1977-78, 147) cita algunos epígrafes cuyos nombres tendrían estas iniciales.

\section{CONCLUSIONES}

Como síntesis de todo lo expuesto y conclusión final hay que señalar las diferencias existentes entre la Bética y Roma, en relación con la técnica edilicia. Ello hace patente la necesidad de estudios para la Península, diferentes a los realizados en Roma, como apuntaba Lugli (46) y la aplicación de una metodología adecuada para ello.

En la Bética no existe, como en Roma, un empleo sistemático del opus testaceum, excepto en Itálica. Lo que encontramos es una combinación de técnicas distintas.

Hay que señalar el empleo de la piedra, como material fundamental, en las construcciones de la Bética Romana. Además de los ejemplos ya citados, el estudio de las fortificaciones realizado por JIMÉNEZ (1977) pone de manifiesto la utilización de ladrillos, únicamente, en la ampliación del pomerium de Itálica en el s. II. El resto de las ciudades mantienen sus murallas en piedra: Niebla, Tejada, Hispalis, Carmo, ..., son ejemplos de ello. Como éste, podríamos aludir a otros muchos casos, algunos ya citados, como son los acueductos de Belo, Almuñécar y los Caños de Carmona; los templos de Belo, Córdoba; teatros; anfiteatros, etc...

Como ocurre en otros momentos y para diversos aspectos de la cultura, las diferencias locales van a influir en gran manera en las técnicas constructivas elegidas, existiendo por ello un uso mayoritario del opus testaceum desde época de Trajano y durante el s. II. En Munigua, en la misma época, se emplea la piedra en combinacoón con el ladrillo, dando lugar a un modo de construcción peculiar y característico de esta ciudad. En Carteia, también en el s. I, están utilizando principalmente la piedra, sobre todo para edificios públicos, aunque el ladrillo no está ausente. Por el contrario, sí lo está en Belo, donde hay que esperar al s. IV para que se introduzca este material y tendrá que ser importado del norte de África, de fábricas imperiales.

Se puede deducir, por tanto, que hay una serie de características y circunstancias que van a influir en la adopción de unos u otros sistemas constructivos. En primer lugar estaría la posibilidad de obtener un determinado material: la existencia de can-

(46) Lugli (1957), al estudiar las técnicas constructivas en provincias itálicas exponía, las diferencias con la obra romana y la necesidad de hacer estudios particulares para cada provincia. 
teras próximas propiciarían el empleo de la piedra y la presencia de suelos arcillosos facilitarían la fabricación de ladrillos. En segundo lugar las posibilidades técnicas: la existencia de una tradición en el uso de la piedra daría como resultado, la experiencia en este trabajo; el conocimiento técnico de fabricación de ladrillos posibilitaría una industria latericia; el potencial humano disponible también influiría, directamente, en la realización de estas actividades (47).

Por último hay que considerar circunstancias políticas, como podría ser la adquisición de un status social determinado; la intencionalidad política de favorecer la ciudad, etc... (48).

En cuanto al uso del opus testaceum, propiamente dicho, tiene características diferentes a las construcciones romanas ya que, los ladrillos que allí se utilizan son, fundamentalmente, de forma triangular. Este tipo - llamado semilater - se emplea durante un gran período de tiempo, desde el s. I, época de Claudio. Sin embargo, los empleados en la Bética son casi siempre rectangulares. Únicamente existen, en lo hasta ahora estudiado, ladrillos triangulares en el acueducto de Itálica.

Ya se ha dicho que los ladrillos de edificios de la Bética, durante los s. I y II, miden, generalmente,

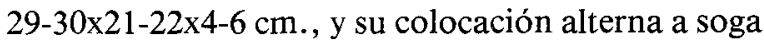
y tizón. En Roma, los ladrillos triangulares utilizados en el s. I, miden desde 20 a $30 \mathrm{~cm}$. de lado y $3-4,5 \mathrm{~cm}$., todo lo más $5 \mathrm{~cm}$., de grosor; las juntas de argamasa horizontales de 0,5 a $1,5 \mathrm{~cm}$., en los primeros años del Imperio y 1 a casi $2 \mathrm{~cm}$. posteriormente (época de Nerón en adelante). Por tanto, los ladrillos empleados en la Bética, exceptuando los de la Terma de Trajano, son mucho más gruesos que éstos y apenas varían a lo largo de los s. I y II. Las juntas de argamasa coincidirán durante el s. I y serán algo más gruesas en la Bética para el s. II.

(47) Esta técnica implica según Gros $(1978,42)$, igual que ocurre con el opus reticulatum, una infraestructura capaz de producir elementos normalizados; equipos de constructores capaces de respetar un esquema preestablecido. Todo ello supone, según este autor una economía esclavista con alto nivel de concentración con una organización jerárquica y una racionalización de los medios.

(48) En este sentido, Gros (1978) ha realizado un buen estudio para Roma y el Lacio en los dos últimos siglos de la República. Trabajos de estas características están por realizar en la Península.
Es, por tanto, casi imposible establecer períodos cronológicos similares a los de Roma a través de las medidas de los ladrillos y, por consiguiente, de su módulo.

El uso de sellos en los ladrillos tiene también diferentes características en ambas zonas. El mayor empleo de ellos se da, en Roma, en época de Adriano. Uno de cada dos o tres ladrillos se sella, mientras que en época de Trajano se da en menor proporción, tan sólo uno de cada quince (BLOCH, 1947, 321). Sin embargo, en Itálica únicamente hay ladrillos con sellos en las termas de Trajano. En cuanto a su tipología, no sólo éstos, sino también otros hallados en la península son diferentes y aparecen esporádicamente.

La ausencia de apoyos básicos, como son la comparación de los edificios con los de Roma y el uso de sellos fechables, imposibilita establecer pautas cronológicas para la utilización del opus testaceum en la Bética. Por otro lado, la disparidad existente entre unas y otras ciudades de la propia Bética evidencia la necesidad de investigaciones de carácter más amplio. Su realización, en el ámbito de la península, podría proporcionar pautas generales basadas en las posibles concomitancias cronológicas y culturales que si reducimos a la Bética, no es posible establecer. No obstante, creemos que las conclusiones obtenidas, al margen de los datos que por sí mismas aportan para el conocimiento de la técnica edilicia romana en Hispania, constituyen una adecuada base documental, a considerar en futuros trabajos.

\section{BIBLIOGRAFÍA}

ALBERTOS FIRMAT, L. 1966: Onomástica primitiva de Hispania Tarraconense y Bética, Salamanca.

ARGENTE, J. L. y OTROS, 1980: Tiermes I, EAE, 111.

BENDALA GALÁN, M. 1975: «Un templo en la Itálica republicana», XIII CNA, Zaragoza, 282-338.

BERMÚDEZ, A. 1987: «Producción latericia y comercio a media distancia en época romana. Un ejemplo en el Mediterráneo noroccidental: Lucius Heredius Optatus. Marcus y Caston, officinatores», Jornadas Internacionals D'Arqueología Romana. Homenatge a Josep Estrada Garriga, 364-371.

BLAKE, M. E. 1959: Roman Construction in Italy from Tiberius throught the Flavian, Washington.

- 1947: Ancient Roman constructions in Italy from the Prehistoric period to August, Washington.

BLAKE, M. E. y TAYLOR BISHOP, D. 1973: Roman construction in Italy from Nerva throught the Anonines, Filadelfia. 
BLOCH, H. 1947: I bolli laterici e la Storia de la edilizia romana, Roma.

BONEVILLE, J. N; DARDAINE, S; DIDIERJEAN, F; LE ROUX, P. y SILLIERES, P. 1981: «La quinzième campagne de Fouilles de la Casa de Velázquez, $M C V, 17$, 393-456.

CANTÓ, A. 1979: «El acueducto romano de Itálica», $M M, 20$, 282-338.

CARRIAZO ARROQUIA, J. de M. 1935: «Estado actual de las excavaciones en Itálica», Homenaje a J. R. Melida III, Madrid, 305-309.

CORZO, R. 1982; «Organización del territorio y evolución urbana en Itálica», Itálica (Santiponce, Sevilla), EAE, 121, 299-319.

CHAVES TRISTÁN, F. 1979: Las monedas hispanorromanas de Carteia, Barcelona.

DARDAIN, S.; BONNEVILLE, J. N. 1980: «La campagne de Fouilles d'Octobre 1979, à Belo», $M C V, 16,375-420$.

DARDAIN, S., MENANTEAU, J. L. y OTROS 1983: Belo II, Historique des Fouilles. Belo et son environnement (Serie Archaeológie IV).

DOMERGUE, 1973: Belo I, París.

ESTEVE Y GUERRERO, M. 1961: «Marcas de un fabricante de vidrios y otros hallazgos inéditos en Asta Regia» $A$ Esp $A, 39,206-208$.

ETIENNE, R. y MAYET, F. 1971: «Briques de Belo. Relations entre la Mauretanie Tingitana et la Bétique, au Bas Empire», $M C V, 7,59-74$

ETIENNE, R., FABRE, G. y L'EVEQUE, P. 1976: Fouilles de Conimbriga II. Epigraphie et sculpture, París.

GARCÍA Y BELLIDO, A. 1960: Colonia Aelia Augusta Itálica (Biblioteca Archaeológica II), Madrid.

- 1968: "Catálogo de los sellos latericios de la Legio VII Gémina en España», Nueve estudios sobre la Legio VII Gémina, León.

- 1970: «Estudios sobre la Legio VII Gémina y su campamento en León, Legio VII Gémina, León.

GILBERT PICARD, CH. 1970: «Note sur le Théâtre romain de Belo», $M C V$, 6, 43-52.

GRUNHAGEN, W. 1959: «Excavaciones en el santuario de terrazas de Munigua», V CNA, Zaragoza, 257-283.

- 1976: "Eine Weibung Für Dis Pater in Munigua», $M M$, 17, 226-237.

- 1977: «Die Statue einer Nymphe aus Munigua», $M M, 18$, 272-283.

GRUNHAGEN, W. y HAUSCHILD, TH. 1977: «Sucinto informe de las excavaciones arqueológicas en Munigua, 1973», NAH, 5, 105-118.

- 1979: «Informe de las excavaciones arqueológicas en Munigua, campaña de 1974, 1975 y 1976», NAH, 6, 281-308.

HAUSCHILD, TH. 1969: «Excavaciones en Munigua en 1966», $C N A, \mathrm{X}$, Zaragoza, 400-408.

- 1969-70: «Munigua, exploraciones en el área de la ciudad al Este del Foro», NAH, XIII-XIV, 61-122.

- 1985: «Munigua, informe preliminar sobre las excavaciones de la casa 1 y 6 (campaña de 1982)», $N A H, 23,235-268$.
HELEN, T. 1975: Organization of Roman Brick production in the first and second centuries $A . D$. An interpretation of Roman Brick Stamps, Helsinki.

JIMÉNEZ, A. 1977: «Arquitectura romana de la Bética I. Introducción al estudio de las fortificaciones», Symposium Segovia y la arqueología romana, 223-238.

LEÓN, P. 1977-78: «Notas sobre la técnica edilicia en Itálica», A Esp A, 50-51, 143-169.

- 1982: «La zona monumental de la nova urbs», Itálica, (Santiponce, Sevilla), EAE, 121, 97-132.

- 1983: «Itálica. Problemática de la superposición de Santiponce al yacimiento", Arqueologia de las ciudades modernas superpuestas a las antiguas, Zaragoza, 213-230.

LUGLI, G. 1957: Técnica edilizia Romana con particolari riguardo a Roma e Lazio, Roma.

LUZÓN, J. M. 1982: «El teatro de Itálica», Symposium El teatro en la Hispania Romana, Madrid, 183-202.

- 1982b: La Itálica de Adriano, Sevilla (3. ${ }^{\mathrm{a}}$ ed.).

MAYET, F. 1974: «Belo, campaña de 1970», A Esp A, 79, 95-107.

PELLICER, M. 1982: «Excavaciones en Itálica (1978-1979). Muralla, cloaca y cisternas», Itálica (Santiponce, Sevilla), EAE, 121, 205-224.

PONSICH, M., MENANTEAU, L. y ROUILLARD, P. 1977: «Metodología y localización de las colonias fenicias de las costas ibéricas» Habis, 8, 217 ss.

PONSICH, M. 1980: «El teatro de Belo», NAH, 10.

PRESEDO, F., MUÑIZ COELLO, T. y OTROS, 1982: Carteia, $E A E, 120$, Madrid.

PRESEDO, F. y CABALLOS RUFINO, A. 1986: «La ciudad de Carteia: estado de la cuestión y primeros resultados de la campaña de 1985», I Congreso Peninsular de H. ${ }^{a}$ Antigua, Santiago de Compostela.

ROMERO DE TORRES, E. 1909: «Las ruinas de Carteia», $B$ Ac Hist, LIV, Madrid.

SERRANO RAMOS, E. y LUQUE MORAÑO, A. 1976: «Memoria de las excavaciones de Manguara y San José, Cartama (Málaga)», NAH, 4, 489-546.

SETALA, P. 1977: Private Domini in Roman Brick Stamps of the Empire. An historical and prosopographical Study of Landowners in the disctrict of Rome, Helsinki.

STEINBY, M. 1974: «I bolli laterizi degli Antiquari del Foro e del Palatino», Mem Acc Linc, 61-109.

- 1974-75: «La cronología delle figlinae doliare urbane dalla fine dell età republicana fino all inizio del III secolo», $B C A R$, LXXXIV, 7-132.

- 1979: «La produzione laterizia», Pompei, 79. Raccolta di Studi per el decimonono centenario dell eruzione vesuviana a cura di F. Zevi, Naples, 265-271.

VAN DEMAN, E. B. 1912: «Methods of determining the date of Roman Concrete Monuments", AJA, second series, Journal of the Archaeological Institute of America, XVI, n. ${ }^{\circ}$ 2. 387-432.

VENY, C. 1965: «Algunas marcas de ladrillos y tejas encontradas en Mallorca》, $A$ Esp $A, 38-39,156-166$.

WOODS, D. COLLANTES, F y FERNÁNDEZ CHICARRO, C. 1967: Carteia, EAE, 58, Madrid. 